NBER WORKING PAPER SERIES

\title{
INTERMEDIATION AS RENT EXTRACTION
}

\author{
Maryam Farboodi \\ Gregor Jarosch \\ Guido Menzio \\ Working Paper 24171 \\ http://www.nber.org/papers/w24171
NATIONAL BUREAU OF ECONOMIC RESEARCH
1050 Massachusetts Avenue
Cambridge, MA 02138 \\ December 2017
}

We thank our audiences at various seminars and conferences. We are especially grateful to Fernando Alvarez, Manuel Amador, Kenneth Burdett, Francesco Lippi, Paolo Martellini, Adrian Masters, Claudio Michelacci, Jesse Perla, Robert Shimer, and Randy Wright for their comments. The views expressed herein are those of the authors and do not necessarily reflect the views of the National Bureau of Economic Research.

At least one co-author has disclosed a financial relationship of potential relevance for this research. Further information is available online at http://www.nber.org/papers/w24171.ack

NBER working papers are circulated for discussion and comment purposes. They have not been peer-reviewed or been subject to the review by the NBER Board of Directors that accompanies official NBER publications.

(C) 2017 by Maryam Farboodi, Gregor Jarosch, and Guido Menzio. All rights reserved. Short sections of text, not to exceed two paragraphs, may be quoted without explicit permission provided that full credit, including $\odot$ notice, is given to the source. 
Intermediation as Rent Extraction

Maryam Farboodi, Gregor Jarosch, and Guido Menzio

NBER Working Paper No. 24171

December 2017

JEL No. D40

\begin{abstract} bargaining.

Maryam Farboodi

26 Prospect Ave

Bendheim Center for Finance

Princeton University

Princeton, NJ 08540

farboodi@princeton.edu

Gregor Jarosch

Department of Economics

Stanford University

579 Serra Mall

Palo Alto, CA 94305

and NBER

gregorjarosch@gmail.com

Guido Menzio

Department of Economics

University of Pennsylvania

467 McNeil Building

3718 Locust Walk

Philadelphia, PA 19104

and NBER

gmenzio@econ.upenn.edu
\end{abstract}

We propose a theory of intermediation as rent extraction, and explore its implications for the extent of intermediation, welfare and policy. A frictional asset market is populated by agents who are heterogeneous with respect to their bargaining skills, as some can commit to take-it-or-leaveit offers and others cannot. In equilibrium, agents with commitment power act as intermediaries and those without act as final users. Agents with commitment trade on behalf of agents without commitment to extract more rents from third parties. If agents can invest in a commitment technology, there are multiple equilibria differing in the fraction of intermediaries. Equilibria with more intermediaries have lower welfare and any equilibrium with intermediation is inefficient. Intermediation grows as trading frictions become small and during times when interest rates are low. A simple transaction tax can restore efficiency by eliminating any scope for 


\section{Introduction}

Search theory has been successfully used to understand labor markets (e.g., Mortensen and Pissarides 1994, Burdett and Mortensen 1999), product markets (e.g., Burdett and Judd 1983, Rubinstein and Wolinsky 1987), and financial markets (e.g., Kiyotaki and Wright 1991, Duffie, Gârlenau and Pedersen 2005). One of the central features of search theory is that, when a buyer and a seller meet, there is no competitive force to uniquely pin down the terms of trade, as both buyer and seller would have to spend time or other resources to contact some alternative trading partners. Stuck in a bilateral monopoly, buyer and seller have some room to bargain over the terms of the trade. While the literature has devoted a great deal of attention to understanding the implications of different bargaining environments (e.g., Diamond 1971, Mortensen 1982, Hosios 1989), it has paid almost no attention to understanding the implications of heterogeneity in the bargaining skills of different traders. Yet, this research question seems both natural, as traders most likely differ with respect to their bargaining skills, and timely, as the recent focus of macroeconomics is the analysis of models with heterogeneous agents.

In this paper, we carry out a systematic study of the implications of heterogeneity in bargaining skills in a search-theoretic model of a financial market. We consider the market for an indivisible asset in fixed supply (e.g., housing, fine art, financial instruments traded in overthe-counter markets, etc...). The market is subject to search frictions, in the sense that agents cannot trade the asset in a central exchange, but need to locate a trading partner. The search process is modeled as a Poisson rate of arrival for a trading partner selected at random from the population. The agents populating the market are heterogeneous with respect to their valuation of the dividend of the asset and with respect to their bargaining skills. Heterogeneity in valuation is modeled as a time-varying agent-specific state which can be either High or Low. Heterogeneity in bargaining skills is modeled as a permanent agent-specific state which can be either Tough or Soft. When two agents meet, they bargain over the terms of trade. Tough agents can commit to make a take-it-or-leave-it offer to their counterpart. Soft agents cannot commit, and either find themselves on the receiving end of a take-it-or-leave-it offer or they trade offers with their counterpart following the textbook alternating-offer protocol of Rubinstein (1982).

In the first part of the paper, we characterize the equilibrium of the asset market, taking as given the fraction of agents with and without commitment. We show that the unique market equilibrium is such that agents without commitment act as final users-in the sense that they buy the asset only when their valuation is high and only sell it when their valuation is low-while agents with commitment act as intermediaries-in the sense that they buy the asset from and sell it to final users irrespective of their own valuation. In particular, an agent with commitment buys from a low-valuation trader without commitment even when he himself has a low valuation for the asset, and sells to high-valuation trader without commitment even when he himself has a 
high valuation for the asset. The agent with commitment intermediates the asset for the agent without commitment only because he can extract more rents when reselling (or repurchasing) the asset to a third party. In this sense, intermediation is a pure rent-extraction activity.

The rent-extraction intermediation carried out by the agents with commitment is socially worthless, because it does not lead to any improvement in the allocation of the asset among low and high valuation traders. Rent-extraction intermediation is also socially harmless, because, in our simple model, it does not lead to any worsening of the asset allocation. However, in more general environments, rent-extraction intermediation leads to an inefficient pattern of trade. This is the case if, for example, the transaction of the asset is costly, the preferences for the dividend of the asset are a continuous variable, or if agents with commitment have a lower meeting rate than agents without commitment.

In the second part of the paper, we characterize the equilibrium of the asset market given that the fraction of agents with and without commitment power is endogenous. We assume that, upon entering the market, agents have the option to acquire a technology that allows them to commit to take-it-or-leave-it offers. While quite abstract, the idea that an agent can acquire the power to commit to his offers is not far-fetched. An agent may acquire commitment power by hiring a sales staff without discretionary power over prices, or by setting up a technology that makes his trading history public and thus allows him to build a reputation for not negotiating prices. A broader interpretation is that all agents have the power to commit to their offers, but that only those who have spent some resources learning about strategic bargaining do exercise it.

We show that, in general, there are multiple equilibria. Different equilibria are associated with a different fraction of agents who acquire the commitment technology and, hence, with a different fraction of intermediaries. There are multiple equilibria because the benefit to an individual agent of acquiring the power to commit to take-it-or-leave-it offers is a hump-shaped function of the fraction of intermediaries in the market. Intuitively, when there are no intermediaries in the market, the outside option of final users is high and, for this reason, the additional rents that an agent can extract from them by having commitment power is low. When there are some intermediaries, the outside option of final users is low and, for this reason, the additional rents that an agent can extract from them by having commitment power is high. When there are many intermediaries, there are very few final users from which an agent with commitment can extract rents.

We also show that equilibria are welfare-ranked. In particular, the higher the equilibrium fraction of intermediaries, the lower is aggregate welfare. Moreover, any equilibrium in which the fraction of intermediaries is positive is inefficient. These results are intuitive, as rentextraction intermediation is an activity that does nothing to improve the allocation of the asset 
among low and high-valuation agents, but it does require investing resources in the commitment technology.

We find that rent-extraction intermediation does not vanish when search frictions become smaller and smaller. Intuitively, as frictions become smaller, there are two countervailing effects on the incentive for an individual agent to acquire commitment and become an intermediary. On the one hand, as frictions become smaller, the outside option of final users improves and, thus, the amount of additional rents that an agent can extract from them by having commitment power falls. On the other hand, as frictions become smaller, the frequency at which an agent meets a final user from which he can extract additional rents by having commitment power increases. The second effect always dominates and, hence, the fraction of agents who acquire commitment power to become intermediaries grows as search frictions vanish. Moreover, at any interior equilibrium, the increase in the fraction of intermediaries is so large that welfare declines. We also find that rent-extraction intermediation becomes more prevalent (and welfare declines) when the interest rate on investments alternative to the commitment technology falls.

The inefficiency of rent-extraction intermediation motivates the last part of the paper, in which we study the effect of a transaction tax. We find that the equilibrium pattern of trade varies with the size of the transaction tax. If the tax is low enough, the pattern of trade is the same as in the laissez-faire equilibrium. If the tax takes on intermediate values, the asset is sold by low to high-valuation agents, but intermediation trades break down. If the tax is high enough, all trade breaks down. We find that the tax reduces the benefit to invest in the commitment technology and, hence, the extent of rent-extraction intermediation. Finally, we identify the transaction tax that maximizes welfare. We show that the optimal transaction tax is such that the after-tax gains from trade between a low and a high-valuation agent are set to zero. This transaction tax is optimal because it induces low valuation agents to sell the asset to high valuation agents (which guarantees the efficiency of the asset allocation), while removing any incentive for agents to acquire commitment power (which guarantees that no resources are wasted on the commitment technology). Intuitively, the optimal transaction tax removes the incentive to invest in bargaining skills by artificially shrinking the (after-tax) gains from trade to zero and, hence, by eliminating any scope for bargaining.

Fundamentally, our paper is a contribution to search theory, as it analyzes the implications of heterogeneity in bargaining skills in markets with trading frictions. While the paper carries out the analysis in the context of an asset market, its results are likely to apply more generally to other frictional markets. From the perspective of search theory, the paper contains four novel insights. First, heterogeneity in bargaining skills leads to additional trade, as agents with the same valuation for the asset but different bargaining skills have an incentive to trade in order to take advantage of third parties. Second, if bargaining skills can be acquired at a cost, there are typi- 
cally multiple equilibria, because of a (local) strategic complementarity across different agents in the decision to acquire bargaining skills. This source of multiplicity is different from those generally highlighted in search theory, such as increasing returns to matching (Diamond 1982), increasing returns to production (Mortensen 1999), and external effects of bilateral matching decisions on the composition of the pool of searchers (Burdett and Coles 1997, Kaplan and Menzio 2016). Third, equilibrium is typically inefficient. The source of inefficiency is distinct from the one generally highlighted in search theory, which stems from the discrepancy between private and social return to searching when the matching function is concave (Mortensen 1982, Hosios 1990). In contrast, the inefficiency highlighted here is due to the fact that the return from acquiring bargaining skills is positive for an individual, but zero for society. Fourth, a transaction tax that brings the after-tax gains from trade to zero restores efficiency, as it eliminates any scope for bargaining and, consequently, for having better bargaining skills.

In a narrower sense, the paper is a contribution to intermediation theory. Rubinstein and Wolinsky (1987, henceforth RW) show, in the context of a product market, that agents who neither produce nor consume a good act as intermediaries if they have a higher meeting rate. Nosal, Wong and Wright $(2015,2016)$ generalize RW by allowing meeting rates, holding costs, and bargaining power to be different for producers, consumers, and potential middlemen. Farboodi, Jarosch and Shimer (2017) further develop RW by endogenizing the agents' choice of meeting rates. The literature has also proposed theories of intermediation not based on differences in meeting rates. Hugonnier, Lester and Weill (2016) show, in the context of an asset market, that agents with a milder valuation for the dividend of the asset act as intermediaries. Kiyotaki and Wright (1989) show, in the context of a product market, that goods with a low holding cost may be used as commodity money and agents who neither produce nor consume these goods may effectively act as middlemen. Wright and Wong (2014) recognize and explore the deep analogies between monetary and intermediation theory. We contribute to this literature by showing that, in the context of an asset market, agents with superior bargaining skills act as intermediaries, even though they have the same meeting rate and valuation for the dividend of the asset as everybody else. This insight leads to a theory of intermediation as pure rent-extraction activity, which we show has distinctive implications in terms of equilibrium, welfare and policy. Within the intermediation literature, Masters (2007) is the paper closest to ours. In the context of a version of Diamond (1982), Masters (2007) shows that agents who have simultaneously high costs of production and high bargaining power act as intermediaries. ${ }^{1}$

\footnotetext{
${ }^{1}$ As far as we know, Masters (2007) is the only other paper that connects heterogeneity in bargaining skills with intermediation. However, his model and ours are very different. In the context of his product market model, gains from trade are fundamentally static. In the context of our asset market model, gains from trade are dynamic. This is why, for instance, agents who have superior bargaining skills become intermediaries if they also have higher production costs in Masters (2007), while agents only need superior bargaining skills to become intermediaries in our model.
} 
Our paper also relates to the literature on financial markets with search frictions (often referred to as over-the-counter markets). The literature was pioneered by Duffie, Gârleanu and Pedersen (2005, henceforth DGP), who study an over-the-counter market with investors and dealers. Investors, who have a time-varying valuation for the dividend of the asset, occasionally meet with other investors and with dealers. Dealers occasionally meet with investors and have access to a frictionless interdealer market. Thus dealers have a higher contact rate than investors and, for this reason, they end up acting as intermediaries by buying the asset at a discount from low-valuation investors and selling the asset at a premium to high-valuation investors. Lagos and Rocheteau (2009) study a version of DGP in which the asset is divisible and Lagos and Rocheteau (2007) further build on this extension by endogenizing the measure of dealers. Hugonnier, Lester and Weill (2016) consider a version of DGP without dealers where the agents' valuation for the asset is a continuous variable. Üslü (2016) studies a version of DGP without dealers where the asset is divisible, valuations are continuous, and agents are heterogeneous with respect to contact rates. Our model is a version of DGP in which there are no dealers and investors differ with respect to their bargaining skills. Moreover, the focus of our paper is not on the size of the bid-ask spreads, as in much of this literature, but on the extent, determinants and welfare consequences of rent-extraction intermediation.

\section{Environment}

We consider the market for an indivisible asset. The supply of the asset is fixed and of measure $A=1 / 2$. The market for the asset is populated by a measure 1 of heterogeneous agents. An agent's type is described by a couple $\{i, j\}$, where $i=\{S, T\}$ denotes the agent's commitment power and $j=\{L, H\}$ denotes the agent's valuation of the asset. The labels $S$ and $T$ stand for Soft and Tough. The labels $L$ and $H$ stand for Low and High. The first dimension of an agent's type is permanent. The measure of agents without commitment power $S$ is $\phi_{S}$, with $\phi_{S} \in[0,1]$, and the measure of agents with commitment power $T$ is $\phi_{T}=1-\phi_{S}$. The second dimension of an agent's type is transitory. In particular, an agent's valuation switches at Poisson rate $\sigma>0$. An agent can either hold 0 or 1 units of the asset. An agent of type $\{i, j\}$ gets flow utility $u_{j}$ when holding the asset, with $u_{H}>u_{L}>0$ and $\Delta u \equiv u_{H}-u_{L}$. An agent gets flow utility 0 when he does not hold the asset. Agents have linear utility with respect to a numeraire good, which is used as a medium of exchange. Agents discount future utilities at the rate $r>0$.

Trade is bilateral and frictional. In particular, one agent meets another randomly-selected agent at Poisson rate $\lambda>0$. If the meeting involves two agents with identical asset holdings, there is no opportunity to trade. If an agent with the asset meets an agent without the asset, there is a trading opportunity. The terms of trade depend on the commitment power of the two agents. In particular, if an agent of type $T$ meets an agent of type $S$, the agent of type $T$ makes 
a take-it-or-leave-it offer to the agent of type $S$. The offer consists of $P$ units of the numeraire good to be exchanged for the ownership of the asset. If two agents of type $T$ meet, one is randomly selected to make a take-it-or-leave-it offer to the other. If two agents of type $S$ meet, they play an alternating-offer bargaining game à la Rubinstein (1982) with a risk of breakdown $\delta>0$. We assume that the bargaining game takes place in virtual time and consider the limit for $\delta \rightarrow 0 .^{2}$

A few comments about the environment are in order. First, we assume that agents differ with respect to their valuation of the asset and that an agent's valuation changes over time. The assumption is common in the literature and is meant to capture either, literally, variation across agents and over time in the utility obtained from holding the asset or, in reduced-form, variation across agents and over time in the ability to hedge any risk associated with the dividend of the asset. This assumption is needed to guarantee that the asset is traded. Indeed, if all agents had the same valuation, the asset would not be traded. If agents had different valuations but these valuations were constant over time, the asset would eventually end up in the hands of the high-valuation agents and trade would stop.

Second, we assume that agents differ with respect to their ability to commit to take-it-orleave-it offers. The assumption is the main difference between our environment and the previous literature and, as we shall see, it generates non-fundamental trades. The assumption can be interpreted as saying that some agents can commit to posted prices-because, e.g., they can delegate trade to representatives without the authority to accept/propose any price different from the one pre-specified by the agent-while some agents cannot commit to post prices and, hence, end up bargaining over the terms of trade.

Third, we assume that the measure of the asset is half the measure of the population and that the stochastic process for the agent's valuation guarantees that, in a stationary equilibrium, exactly half of the agents have a high valuation and half have a low valuation. These assumptions are made for tractability, as they allow us to focus on symmetric equilibria. That is, equilibria in which the measure of agents with high valuation without the asset is equal to the measure of agents with low valuation with the asset.

The model is deliberately simple and abstract. Its purpose is to provide a framework in which to think about the effect of heterogeneity in bargaining skills (originating from hetero-

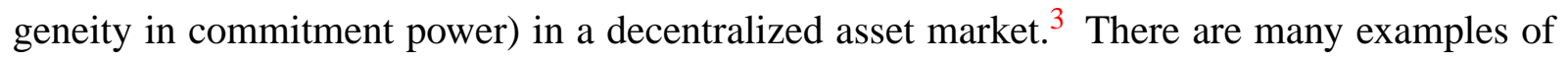

\footnotetext{
${ }^{2} \mathrm{We}$ assume that search is random, in the sense that agents cannot direct their search towards traders of a particular type or, in the case of traders with commitment, towards those posting a particular menu of prices. The assumption is common to all the literature on intermediation (see, e.g., RW, Nosal, Wong and Wright 2015, etc...) and on over-the-counter financial markets (see, e.g, DGP, Lagos and Rocheteau 2009, etc...) that we reviewed in the introduction. We believe that many of our findings would be qualitatively unchanged as long as some fraction of agents search randomly.

${ }^{3} \mathrm{We}$ assume that heterogeneity in bargaining skills is due to the fact that some agents can commit to their offers
} 
decentralized asset market in which agents may have different commitment power. One example is the housing markets. In this market, trade is decentralized, agents have different and time-varying utilities from living in a particular house, and some agents-say developers and flippers-may be able to commit to take-it-or-leave-it offers, while other agents may bargain. Another example is the fine art market. In this market, trade is typically decentralized, agents have different and time-varying valuations for the same piece of art, and some agents-say art gallerists-may be able to commit to take-it-or-leave-it offers. Finally, as pointed out by DGP, there are some financial asset markets (over-the-counter markets) that operate in a decentralized fashion. It is not far-fetched to think that, in these markets, some agents may have more commitment power than others.

\section{Market Equilibrium}

In this section, we characterize the equilibrium of the asset market while taking as given the measure of agents of type $S$ and $T$. We refer to this as the market equilibrium. We first establish the existence and uniqueness of a symmetric stationary market equilibrium in which agents of type $S$ act as final users-buying the asset only when their valuation is $H$ and selling the asset only when their valuation is $L$-and agents of type $T$ act as intermediaries-buying the asset from types $(S, L)$ and selling it to types $(S, H)$ irrespective of their own valuation. This pattern of trade is illustrated in Figure 1. We then rule out the existence of symmetric stationary equilibria with any other pattern of trade. Finally, we discuss the key properties of equilibrium. The main finding in this section is that heterogeneity in the commitment power of different agents naturally generates a theory of intermediation as a pure rent-extraction activity.

\subsection{Conditions for Market Equilibrium}

We want to establish the existence of a symmetric stationary market equilibrium where trade follows the pattern in Figure 1. We denote as $V_{i, j}$ the equilibrium lifetime utility of an agent of type $(i, j)$ who owns the asset, as $U_{i, j}$ the lifetime utility of an agent of type $(i, j)$ who does not own the asset, and as $D_{i, j} \equiv V_{i, j}-U_{i, j}$ the net value of asset ownership. We denote as $P_{i, j}(m, n)$ the equilibrium price at which an agent of type $(i, j)$ sells the asset to an agent of type $(m, n)$. We denote as $\mu_{i, j}$ and $v_{i, j}$ denote the equilibrium measure of agents of type $(i, j)$ who, respectively, own and do not own the asset. Since the equilibrium we are seeking is symmetric,

and some cannot. We choose this to be the source of heterogeneity in bargaining skills because it is consistent with a game-theoretic approach to bargaining. Alternatively, we could have followed the axiomatic approach to bargaining and directly assumed that agents are heterogeneous with respect to their bargaining power. In this alternative environment, agents with high bargaining skills trading with agents with low bargaining skills may capture any fraction of the gains from trade in $(1 / 2,1]$ rather than 1 as in our model. We believe that our results would extend to this alternative environment. 


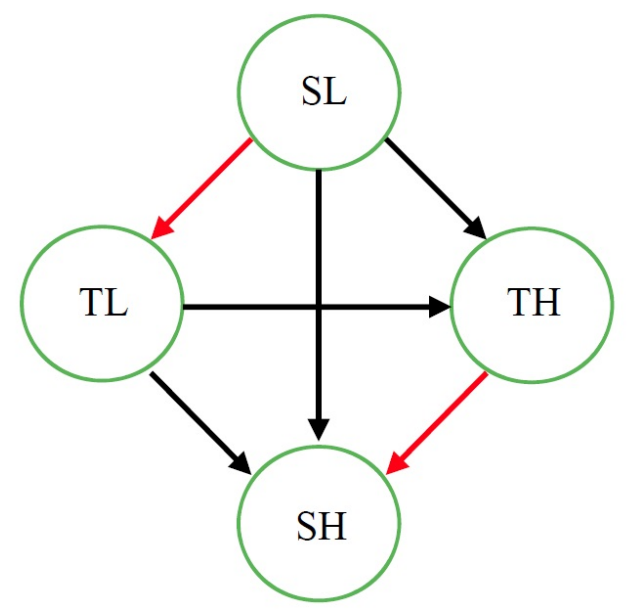

Notes: Dark arrows are fundamental trades, where low-valuation sell to high-valuation agents. Light arrows are intermediation trades, where the asset is exchanged by agents with the same valuation.

Figure 1: Pattern of Trade

the measure $\mu_{i, L}$ of low-valuation agents of type $i$ with the asset must equal the measure $v_{i, H}$ of high-valuation agents of type $i=\{S, T\}$ without the asset. Similarly, $\mu_{i, H}$ must equal $v_{i, L}$. Hence, $\lambda \mu_{i, L}=\lambda v_{i, H} \equiv \lambda_{i}$ and $\lambda \mu_{i, H}=\lambda v_{i, L} \equiv \hat{\lambda}_{i}$. We refer to $\lambda_{i}$ as the rate at which a trader meets a mismatched agent of type $i$ and to $\hat{\lambda}_{i}$ as the rate at which a trader meets a well-matched agent of type $i$.

\subsubsection{Value Functions: Soft Agent}

The equilibrium lifetime utility of an agent of type $(S, L)$ who owns the asset satisfies

$$
\begin{aligned}
r V_{S L} & =u_{L}+\sigma\left(V_{S, H}-V_{S, L}\right)+\lambda_{S}\left(P_{S, L}(S, H)-D_{S, L}\right) \\
& +\lambda_{T}\left(P_{S, L}(T, H)-D_{S, L}\right)+\hat{\lambda}_{T}\left(P_{S, L}(T, L)-D_{S, L}\right) .
\end{aligned}
$$

The agent enjoys a flow utility $u_{L}$. At rate $\sigma$, the agent's valuation of the asset switches from $L$ to $H$ and the agent experiences a change in lifetime utility $V_{S, H}-V_{S, L}$. The agent meets a trader of type $(S, H)$ without the asset at rate $\lambda_{S}$, a trader of type $(T, H)$ without the asset at rate $\lambda_{T}$ and a trader of type $(T, L)$ without the asset at rate $\hat{\lambda}_{T}$. When the agent meets any of these traders, he sells the asset at the price $P_{S, L}(m, n)$, where $(m, n)$ denotes the trader's type, and experiences a change in lifetime utility $-D_{S, L}$.

The price $P_{S, L}(m, n)$ at which the agent $(S, L)$ sells the asset depends on the buyer's type. If the buyer is of type $(S, H)$, the price $P_{S, L}(S, H)$ is determined as the outcome of the Rubinstein (1982) alternating-offer bargaining game. The outcome of the bargaining game is trade 
at a price $P_{S, L}(S, H)$ such that the gains from trade accruing to the buyer equal the gains from trade accruing to the seller. That is, $P_{S, L}(S, H)-D_{S, L}=-P_{S, L}(S, H)+D_{S, H}$ or, equivalently, $P_{S, L}(S, H)=\left(D_{S, H}+D_{S, L}\right) / 2$. If the buyer is of type $(T, n)$, the price $P_{S, L}(T, n)$ is determined as a take-it-or-leave-it offer from the buyer. The buyer's take-it-or-leave-it offer is a price $P_{S, L}(T, n)$ that makes the seller indifferent between accepting and rejecting the trade and, hence, gives him none of the gains from trade. That is, $P_{S, L}(T, n)-D_{S, L}=0$ or, equivalently, $P_{S, L}(T, n)=D_{S, L}$. Substituting these prices in (3.1), we obtain ${ }^{4}$

$$
r V_{S, L}=u_{L}+\sigma\left(V_{S, H}-V_{S, L}\right)+\lambda_{S}\left(D_{S, H}-D_{S, L}\right) / 2
$$

The equilibrium lifetime utility of an agent of type $(S, L)$ who does not own the asset satisfies

$$
r U_{S, L}=\sigma\left(U_{S, H}-U_{S, L}\right)
$$

The agent enjoys a flow utility of 0 . At rate $\sigma$, the agent's valuation of the asset switches from $L$ to $H$ and the agent experiences a change in lifetime utility $U_{S, H}-U_{S, L}$. The agent meets traders at rate $\lambda$. However, no matter whom the agent meets, he does not buy the asset.

Subtracting (3.3) from (3.2), we find that the net value of asset ownership for an agent of type $(S, L)$ satisfies

$$
r D_{S, L}=u_{L}+\sigma\left(D_{S, H}-D_{S, L}\right)+\lambda_{S}\left(D_{S, H}-D_{S, L}\right) / 2
$$

The net value of the asset to the agent can be expressed as the sum of three terms. The first term is the difference in the agent's flow utility when he does and does not own the asset. The second term is the difference in the change in the agent's lifetime utility caused by a preference switch when he does and does not own the asset. The third term is the value to the agent of the option of selling the asset. Since an agent of type $S$ captures half of the gains from trade when selling to a trader of type $S$ and none of the gains from trade when selling to a trader of type $T$, the option value is the rate at which the agent meets a mismatched trader of type $(S, H)$ times half of the gains from trade associated with that meeting.

The equilibrium lifetime utilities of an agent of type $(S, H)$ who owns and does not own the

\footnotetext{
${ }^{4}$ As it is apparent from (3.2), the lifetime utility of an agent is identical whether the agent captures none of the surplus upon meeting a particular type of trader, or whether he never meets that type of trader. This observation, which has been previously made by Postel-Vinay and Robin (2002) and Lagos and Rocheteau (2009), does not imply that the equilibrium of a model in which the agent does not capture any of the surplus upon meeting a particular trader is the same as the equilibrium in which the agent never meets that trader. In fact, the two equlibria are described by different systems of equations, as the lifetime utility of the agent's counterparty is different. In the first case, the lifetime utility of the trader includes a term related to meetings with the agent (because the trader captures all of the surplus in that meeting). In the second case, the lifetime utility of the trader does not include a term related to meetings with the agent (because, if the agent never meets the trader, then the trader never meets the agent).
} 
asset respectively satisfy

$$
r V_{S, H}=u_{H}+\sigma\left(V_{S, L}-V_{S, H}\right)
$$

and

$$
\begin{aligned}
r U_{S, H} & =\sigma\left(U_{S, L}-U_{S, H}\right)+\lambda_{S}\left(-P_{S, L}(S, H)+D_{S, H}\right) \\
& +\lambda_{T}\left(-P_{T, L}(S, H)+D_{S, H}\right)+\hat{\lambda}_{T}\left(-P_{T, H}(S, H)+D_{S, H}\right) .
\end{aligned}
$$

The expression (3.5) is analogous to (3.3). The agent enjoys a flow utility $u_{H}$. At rate $\sigma$, the agent's valuation switches to $L$. The agent meets traders at the rate $\lambda$. However, no matter whom he meets, the agent does not sell the asset. The expression (3.6) is analogous to (3.2). The agents enjoys a flow utility of 0 . At rate $\sigma$, the agent's valuation switches to $L$. The agent meets a trader of type $(S, L)$ with the asset at rate $\lambda_{S}$. When this happens, the agent buys the asset at the price $P_{S, L}(S, H)=\left(D_{S, H}+D_{S, L}\right) / 2$. The agent meets a trader of type $(T, L)$ with the asset at rate $\hat{\lambda}_{T}$ and a trader of type $(T, H)$ with the asset at rate $\lambda_{T}$. When either event happens, the agent receives a take-it-or-leave-it offer $P_{T, n}(S, H)=D_{S, H}$.

Replacing the equilibrium prices in (3.6) and subtracting (3.6) from (3.5), we find that the net value of asset ownership for an agent of type $(S, H)$ satisfies

$$
r D_{S, H}=u_{H}+\sigma\left(D_{S, L}-D_{S, H}\right)-\lambda_{S}\left(D_{S, H}-D_{S, L}\right) / 2
$$

The expression in (3.7) is analogous to (3.4), except that the last term in (3.7) represents the value to the agent of foregoing the option of buying the asset, rather than the value to the agent of acquiring the option of selling the asset.

\subsubsection{Value Functions: Tough Agent}

The equilibrium lifetime utility of an agent of type $(T, L)$ who owns the asset satisfies

$$
\begin{aligned}
r V_{T L} & =u_{L}+\sigma\left(V_{T H}-V_{T L}\right) \\
& +\lambda_{S}\left(P_{T, L}(S, H)-D_{T, L}\right)+\lambda_{T}\left(\mathbb{E}\left[P_{T, L}(T, H)\right]-D_{T, L}\right) .
\end{aligned}
$$

The agent enjoys a flow utility $u_{L}$. At rate $\sigma$, the agent's valuation switches from $L$ to $H$ and the agent experiences a lifetime utility change $V_{T, H}-V_{T, L}$. At rate $\lambda_{S}$, the agent meets a trader of type $(S, H)$ without the asset. When this happens, the agent makes a take-it-or-leave-it offer $P_{T, L}(S, H)=D_{S, H}$ to the trader, sells the asset, and experiences a lifetime utility change $-D_{T, L}$. At rate $\lambda_{T}$, the agent meets a trader of type $(T, H)$ without the asset. When this happens, the agent gets to make a take-it-or-leave-it offer with probability $1 / 2$ and receives a take-it-or-leave it offer with probability $1 / 2$. In the first case, the agent sells at the price $D_{T, H}$, which leaves none of the gains from trade to the buyer. In the second case, the agent sells at the price $D_{T, L}$ which leaves him with none of the gains from trade. In expectation, the agent sells at the price $\mathbb{E}\left[P_{T, L}(T, H)\right]=\left(D_{T, L}+D_{T, H}\right) / 2$ and captures half of the gains from trade. 
The equilibrium lifetime utility of an agent of type $(T, L)$ who does not own the asset satisfies

$$
r U_{T, L}=\sigma\left(U_{T, H}-U_{T, L}\right)+\lambda_{S}\left(-P_{S, L}(T, L)+D_{T, L}\right)
$$

The agent enjoys a flow utility of 0 . At rate $\sigma$, the agent's valuation switches from $L$ to $H$. At the rate $\lambda_{S}$, the agent meets a trader of type $(S, L)$ with the asset. When this happens, the agent makes a take-it-or-leave-it offer $P_{S, L}(T, L)=D_{S, L}$ to the trader, buys the asset and experiences a change in lifetime utility $D_{T, L}$.

Replacing the equilibrium prices in (3.8) and (3.9) and subtracting (3.8) from (3.9), we find that the net value of asset ownership for an agent of type $(T, L)$ satisfies

$$
\begin{aligned}
r D_{T, L} & =u_{L}+\sigma\left(D_{T, H}-D_{T, L}\right) \\
& +\lambda_{S}\left(D_{S, H}-D_{T, L}\right)+\lambda_{T}\left(D_{T, H}-D_{T, L}\right) / 2-\lambda_{S}\left(D_{T, L}-D_{S, L}\right) .
\end{aligned}
$$

The first term in (3.10) is the difference in the agent's flow utility when he does and does not own the asset. The second term is the difference in the change in the agent's lifetime utility caused by a preference switch when he does and does not own the asset. The third and fourth terms together represent the value to the agent of the option of selling the asset. The third term is the rate at which the agent meets a mismatched trader of type $(S, H)$ times the gains from trade associated with that meeting. The fourth term is the rate at which the agent meets a mismatched trader of type $(T, H)$ times half of the gains from trade. The last term represents the value of the foregone option of buying the asset, which is given by the rate at which the agent meets a mismatched trader of type $(S, L)$ times all of the gains from trade.

The lifetime utilities for an agent of type $(T, H)$ who owns and does not own the asset satisfy

$$
r V_{T, H}=u_{H}+\sigma\left(V_{T, L}-V_{T, H}\right)+\lambda_{S}\left(D_{S, H}-D_{T, H}\right)
$$

and

$$
r U_{T, H}=\sigma\left(U_{T L}-U_{T H}\right)+\lambda_{S}\left(D_{T, H}-D_{S, L}\right)+\lambda_{T}\left(D_{T, H}-D_{T, L}\right) / 2 .
$$

The above expressions are easy to understand and imply that the net value of asset ownership for an agent of type $(T, H)$ satisfies

$$
\begin{aligned}
r D_{T, H} & =u_{H}+\sigma\left(D_{T, L}-D_{T, H}\right) \\
& +\lambda_{S}\left(D_{S, H}-D_{T, H}\right)-\lambda_{T}\left(D_{T, H}-D_{T, L}\right) / 2-\lambda_{S}\left(D_{T, H}-D_{S, L}\right) .
\end{aligned}
$$

\subsubsection{Individual Rationality of the Pattern of Trade}

We formulated the value functions taking as given the pattern of trade in Figure 1. This pattern of trade is consistent with equilibrium if and only if the gains from trade are positive in every 
meeting in which the asset is supposed to be exchanged, and they are negative in every meeting in which the asset is supposed not to be exchanged. It is straightforward to see that these conditions are satisfied iff the following chain of inequalities holds

$$
D_{S, L} \leq D_{T, L} \leq D_{T, H} \leq D_{S, H}
$$

Albeit intuitive, let us explain why the pattern of trade is consistent with equilibrium if and only if the gains from trade are positive (negative) in all the meetings where the asset is supposed to be (not to be) exchanged. First, consider a meeting between two agents of type $S$. The agents engage in an alternating-offer bargaining game. If the gains from trade are positive, the outcome of the game is such that the asset is exchanged at a price that equalizes the gains from trade accruing to buyer and seller. If the gains from trade are negative, the outcome of the game is that the asset is not exchanged. Next, consider a meeting between an agent of type $S$ and one of type $T$. If the gains from trade are positive, the agent of type $T$ finds it optimal to make a take-it-or-leave-it offer that leaves the agent of type $S$ just indifferent between accepting and rejecting the trade, and the agent of type $S$ accepts the trade. If the gains from trade are negative, the agent of type $T$ finds it optimal to make a take-it-or-leave-it offer that the agent of type $S$ will reject. Finally, consider a meeting between two agents of type $T$. Irrespective of who makes the take-it-or-leave-it offer, the asset is exchanged if and only if the gains from trade are positive.

\subsubsection{Stationarity of the Distribution}

The distribution of agents $\left\{\mu_{i, j}, v_{i, j}\right\}$ is stationary if and only if the measure of agents who, during an arbitrarily small interval of time of length $d t$, become asset (non-)holders of type $(i, j)$ equals the measure of agents who, during the same interval of time, cease to be asset (non-)holders of type $(i, j)$.

The inflow-outflow equation for agents of type $(i, j)$ who hold the asset is

$$
\mu_{i, j} \sigma+\mu_{i, j} \sum_{m, n}\left[\lambda v_{m, n} \theta_{i, j}(m, n)\right]=\mu_{i, \neg j} \sigma+v_{i, j} \sum_{m, n}\left[\lambda \mu_{m, n} \theta_{m, n}(i, j)\right]
$$

The left-hand side is the flow out of the group, which is given by the sum of two terms. The first term is the measure $\mu_{i, j} \sigma$ of agents of type $(i, j)$ with the asset whose valuation switches from $j$ to $\neg j$. The second term is the measure $\mu_{i, j} \lambda v_{m, n} \theta_{i, j}(m, n)$ of agents of type $(i, j)$ with the asset who meet a trader of type $(m, n)$ without the asset and sell, where $\theta_{i, j}(m, n)$ is an indicator function that takes the value 1 if $(i, j)$ sells to $(m, n)$ according to the equilibrium pattern of trade and 0 otherwise. The right-hand side is the flow into the group, which is also given by the sum of two terms. The first term is the measure $\mu_{i, \neg j} \sigma$ of agents of type $(i, \neg j)$ with the asset whose valuation switches from $\neg j$ to $j$. The second term is the measure $v_{i, j} \lambda \mu_{m, n} \theta_{m, n}(i, j)$ of 
agents of type $(i, j)$ without the asset who meet a trader of type $(m, n)$ with the asset and buy.

The inflow-outflow equation for agents of type $(i, j)$ who do not hold the asset is

$$
v_{i, j} \sigma+v_{i, j} \sum_{m, n}\left[\lambda \mu_{m, n} \theta_{m, n}(i, j)\right]=v_{i, \neg j} \sigma+\mu_{i, j} \sum_{m, n}\left[\lambda v_{m, n} \theta_{i, j}(m, n)\right]
$$

The left-hand side is the flow out of the group, which is given by the sum of the measure of agents of type $(i, j)$ without the asset whose valuation switches to $\neg j$ and the measure of agents of type $(i, j)$ without the asset who buy. The right-hand side is the flow into the group, which is given by the sum of the measure of agents of type $(i, \neg j)$ without the asset whose valuation switches to $j$ and the measure of agents of type $(i, j)$ with the asset who sell.

The distribution of agents has also to satisfy some consistency conditions

$$
\begin{aligned}
\sum_{j}\left(\mu_{S, j}+v_{S, j}\right) & =\phi_{S}, \\
\sum_{j}\left(\mu_{T, j}+v_{T, j}\right) & =\phi_{T}, \\
\sum_{j}\left(\mu_{S, j}+\mu_{T, j}\right) & =1 / 2 .
\end{aligned}
$$

The first condition requires the distribution $\left\{\mu_{i, j}, v_{i, j}\right\}$ to be such that the sum of the measure of agents of type $S$ with and without the asset is equal to the measure $\phi_{S}$ of agents of type $S$. The second condition requires the distribution to be such that the measure of agents of type $T$ with and without the asset is equal to the measure $\phi_{T}$ of agents of type $T$. The third condition requires the distribution to be such that the sum of the measure of agents with the asset is equal to the measure $1 / 2$ of the asset in the market.

\subsubsection{Definition of Market Equilibrium}

We are now in the position to formally define a market equilibrium.

Definition 1 A Stationary Symmetric Market Equilibrium in which trade follows the pattern of Figure 1 is given by net values for asset ownership $\left\{D_{i, j}\right\}$ and a distribution of agents $\left\{\mu_{i, j}, v_{i, j}\right\}$ such that:

(i) Net asset value satisfies Bellman Equations: $\left\{D_{i, j}\right\}$ satisfy (3.4), (3.7), (3.10) and (3.13);

(ii) Trade is individually rational: $\left\{D_{i, j}\right\}$ satisfies condition (3.14);

(iii) Distribution is stationary: $\left\{\mu_{i, j}, v_{i, j}\right\}$ satisfies conditions (3.15)-(3.19);

(iv) Distribution is symmetric: $\left\{\mu_{i, j}, v_{i, j}\right\}$ is such that $\mu_{i, L}=v_{i, H}$ and $\mu_{i, H}=v_{i, L}$ for $i=\{S, T\}$.

\subsection{Existence and Uniqueness of Market Equilibrium}

The first step in establishing the existence of a market equilibrium is to verify that there exists a solution to the system of Bellman Equations (3.4), (3.7), (3.10) and (3.13) for the net values of 
asset ownership $\left\{D_{i, j}\right\}$ that satisfies condition (3.14) for the individual rationality of the pattern of trade illustrated in Figure 1.

To this aim, consider the gains from trade $D_{S, H}-D_{S, L}$ between an agent of type $(S, H)$ without the asset and one of type $(S, L)$ with the asset. From (3.4) and (3.7), it follows that the gains from trade are given by

$$
D_{S, H}-D_{S, L}=\frac{\Delta u}{r+2 \sigma+\lambda_{S}}>0 .
$$

The gains from trade are strictly positive. They are proportional to the difference $\Delta u$ in the valuation of the asset between the prospective buyer and seller. The factor of proportionality is $1 /\left(r+2 \sigma+\lambda_{S}\right)$. The term $r+2 \sigma$ captures the effective duration of the difference in valuation between prospective buyer and seller. The term $\lambda_{S}$ captures the outside options of prospective buyer and seller. The outside option of the prospective buyer, which arrives at the rate $\lambda_{S}$, is to buy the asset from some other agent of type $(S, L)$ and capture half of the gains from trade $D_{S, H}-D_{S, L}$. The outside option of the prospective seller, which also arrives at the rate $\lambda_{S}$, is to sell to some other agent of type $(S, H)$ and capture half of the gains from trade $D_{S, H}-D_{S, L}$.

Next, consider the gains from trade $D_{T, H}-D_{T, L}$ between an agent of type $(T, H)$ without the asset and one of type $(T, L)$ with the asset. From (3.10) and (3.13), it follows that the gains from trade are given by

$$
D_{T, H}-D_{T, L}=\frac{\Delta u}{r+2 \sigma+2 \lambda_{S}+\lambda_{T}}>0
$$

The gains from trade are strictly positive. They are proportional to the difference $\Delta u$ in the valuation of the asset between the prospective buyer and seller. The factor of proportionality is smaller than in (3.20) because the outside options of the prospective buyer and seller are better. In particular, the outside option of the prospective buyer includes purchasing the asset from an agent of type $(S, L)$ and capturing all the gains from trade as well as purchasing the asset from some other agent of type $(T, L)$ and capturing half of the gains from trade. Similarly, the outside option of the prospective seller includes selling the asset to an agent of type $(S, H)$ and capturing all of the gains from trade as well as selling the asset to some other agent of type $(T, H)$ and capturing half of the gains from trade.

Now, consider the gains from trade $D_{T, L}-D_{S, L}$ between an agent of type $(T, L)$ without the asset and one of type $(S, L)$ with the asset. From (3.10) and (3.13), it follows that the gains from trade are given by

$$
D_{T, L}-D_{S, L}=\frac{1}{2}\left[\frac{\lambda_{T}\left(D_{T, H}-D_{T, L}\right)+\lambda_{S}\left(D_{S, H}-D_{S, L}\right)}{r+2 \sigma+2 \lambda_{S}}\right]>0 .
$$

The gains from trade are strictly positive. They are not positive because the prospective buyer 
has a higher valuation for the asset than the prospective seller. They are positive because the prospective buyer can exchange the asset for a higher price than the prospective seller. In fact, the prospective buyer, who has commitment power, can sell the asset to an agent of type $(T, H)$ and capture half rather than none of the gains from trade, and he can sell the asset to an agent of type $(S, H)$ and capture all rather than half of the gains from trade. For this reason, $D_{T, L}-D_{S, L}$ is proportional to $\lambda_{T}\left(D_{T, H}-D_{T, L}\right) / 2+\lambda_{S}\left(D_{S, H}-D_{S, L}\right) / 2$.

Finally, it is easy to show that the gains from trade $D_{S, H}-D_{T, H}$ between an agent of type $(S, H)$ without the asset and one of type $(T, H)$ with the asset are equal to $D_{T, L}-D_{S, L}$ and, hence, strictly positive. Again, the gains from trade are positive not because of difference in valuation between prospective buyer and seller, but because the prospective seller, who has commitment power, can repurchase the asset at a lower price than the prospective buyer.

For arbitrary $\lambda_{S}$ and $\lambda_{T}$, the solution for $\left\{D_{i, j}\right\}$ to the Bellman Equations (3.4), (3.7), (3.10) and (3.13) exists and is unique, as $D_{S, L}$ is uniquely determined by (3.4) and (3.20) and the other values are uniquely determined by (3.20)-(3.22). Moreover, the solution to the Bellman Equations (3.4), (3.7), (3.10) and (3.13) is such that $D_{S, L}<D_{T, L}<D_{T, H}<D_{S, H}$, as we established above that $D_{S, L}<D_{T, L}, D_{T, L}<D_{T, H}$ and $D_{T, H}<D_{S, H}$. We have thus verified that, for arbitrary $\lambda_{S}$ and $\lambda_{T}$, there is a unique solution for $\left\{D_{i, j}\right\}$ to the Bellman Equations and that this solution satisfies condition (3.14) for the individual rationality of the pattern of trade.

The second step in establishing the existence of a market equilibrium is to verify that there is a symmetric distribution of agents $\left\{\mu_{i, j}, v_{i, j}\right\}$ that satisfies the stationarity conditions (3.15)(3.19). It is tedious but straightforward to show that the unique solution to (3.15)-(3.19) is

$$
\begin{gathered}
\mu_{S, L}=v_{S, H}=\sqrt{\left(\frac{\sigma}{\lambda}\right)^{2}+\frac{\sigma}{2 \lambda}+\frac{\phi_{T}^{2}}{16}}-\left(\frac{\sigma}{\lambda}+\frac{\phi_{T}}{4}\right), \\
\mu_{T, L}=v_{T, H}=\frac{\phi_{T}}{4}+\sqrt{\left(\frac{\sigma}{\lambda}\right)^{2}+\frac{\sigma}{2 \lambda}}-\sqrt{\left(\frac{\sigma}{\lambda}\right)^{2}+\frac{\sigma}{2 \lambda}+\frac{\phi_{T}^{2}}{16}}, \\
v_{i, L}=\phi_{i} / 2-\mu_{i, L}, \text { for } i=\{S, T\}, \\
\mu_{i, H}=\phi_{i} / 2-v_{i, H}, \text { for } i=\{S, T\} .
\end{gathered}
$$

The expression in (3.23) shows that the measure of agents of type $(S, L)$ with the asset is equal to the measure of agents of type $(S, H)$ without the asset. The common measure of mismatched agents of type $S$ is strictly increasing in the ratio $\sigma / \lambda$ between the arrival rate of preference shocks and the arrival rate of trading partners. For $\sigma / \lambda \rightarrow 0$, the measure of mismatched agents of type $S$ converges to 0 . For $\sigma / \lambda \rightarrow \infty$, the measure converges to $\phi_{S} / 4$, 
which is what one would obtain if the asset was assigned at random. Similarly, the expression in (3.24) shows that the measure of agents of type $(T, L)$ with the asset is equal to the measure of agents of type $(T, H)$ without the asset. The common measure of mismatched agents of type $T$ is strictly increasing in $\sigma / \lambda$. For $\sigma / \lambda \rightarrow 0$, the measure of mismatched agents of type $T$ converges to zero. For $\sigma / \lambda \rightarrow \infty$, the measure converges to $\phi_{T} / 4$.

The expression in (3.25) shows that the measure of agents of type $(i, L)$ with the asset plus the measure of agents of type $(i, L)$ without the asset is equal to half of the measure of agents of type $i=\{S, T\}$. This finding is intuitive, as the symmetry of the preference shocks guarantee that half of the population of agents of type $i$ has low valuation. For the same reason, (3.26) states that the measure of agents of type $(i, H)$ with and without the asset is equal to half of the measure of agents of type $i=\{S, T\}$.

For arbitrary $\left\{D_{i, j}\right\}$, the distribution $\left\{\mu_{i, j}, v_{i, j}\right\}$ that satisfies the stationarity conditions (3.15)-(3.19) exists and is uniquely given by (3.23)-(3.26). Moreover, the distribution in (3.23)(3.26) is symmetric, as $\mu_{i, L}=v_{i, H}$ and $\mu_{i, H}=v_{i, L}$ for $i=\{S, T\}$. We have thus verified that, for arbitrary $\left\{D_{i, j}\right\}$, there exists a unique distribution of agents $\left\{\mu_{i, j}, v_{i, j}\right\}$ that satisfies the stationarity conditions (3.15)-(3.19) and that such distribution is symmetric.

This completes the proof of existence and uniqueness of a symmetric stationary equilibrium in which trade follows the pattern illustrated in Figure 1. In Appendix A, we also prove that there is no symmetric stationary market equilibrium with a different pattern of trade. These findings are summarized in the proposition below.

\section{Proposition 2 Existence and Uniqueness of Market Equilibrium.}

(i) For any given $\phi_{T} \in[0,1]$, there exists a unique stationary symmetric market equilibrium in which trade follows the pattern illustrated in Figure 1.

(ii) For any given $\phi_{T} \in[0,1]$, there exists no other symmetric stationary market equilibrium.

\subsection{Properties of Market Equilibrium}

The first notable property of the market equilibrium is that market participants endogenously sort themselves into intermediaries and final users. The agents of type $S$, who do not have the ability to commit to prices, become final users, in the sense that they buy the asset only when their valuation is high and they sell it only when their valuation turns low. The agents of type $T$, who have the ability to commit to prices, become intermediaries, in the sense that they buy and sell the asset to final users independently of their own valuation for the asset.

The second notable property of equilibrium is that intermediation is a rent-extraction activity. In the equilibrium pattern of trade illustrated in Figure 1, there are six types of trades. Four of these trades are fundamental trades ( $S L$ to $S H, S L$ to $T H, T L$ to $T H$ and $T L$ to $S H$ ), in the 
sense that the asset is sold by a low-valuation agent and bought by a high-valuation agent. Two of these trades are intermediation trades ( $S L$ to $T L$ and $T H$ to $S H$ ), in the sense that the asset is exchanged even though buyer and seller have the same valuation for the asset. Both types of intermediation trades are generated by the $T$-agents' superior ability to extract rents in future trades. When a low-valuation agent of type $T$ purchases the asset from a low-valuation agent of type $S$, he does not do so because he values the asset more or because he can find a highvaluation buyer more quickly. The low-valuation agent of type $T$ purchases the asset because he can use his commitment power to sell the asset to a high-valuation buyer at a higher price. Similarly, when a high-valuation agent of type $T$ sells the asset to a high-valuation agent of type $S$, he does not do so because he values the asset less or because he can find another unit of the asset more quickly. The high-valuation agent of type $T$ sells the asset because he can go back to the market and purchase another unit of the asset at a lower price.

The incentives for agents of type $T$ to become intermediaries are embodied in the equilibrium prices

$$
\begin{aligned}
P_{S, L}(S, H) & =\mathbb{E}\left[P_{T, L}(T, H)\right]=\frac{u_{L}+u_{H}}{2 r}, \\
P_{S, L}(T, n) & =\frac{u_{L}+u_{H}}{2 r}-\frac{1}{r+2 \sigma+\lambda_{S}} \frac{\Delta u}{2}, \\
P_{T, n}(S, H) & =\frac{u_{L}+u_{H}}{2 r}+\frac{1}{r+2 \sigma+\lambda_{S}} \frac{\Delta u}{2} .
\end{aligned}
$$

The average price for the asset is $\left(u_{L}+u_{H}\right) / 2 r$. If an agent of type $S$ sells to another agent of type $S$, the exchange take place at the average price. If, instead, an agent of type $T$ sells to an agent of type $S$, the exchange takes place at the average price plus a premium. Similarly, if an agent of type $S$ buys from another agent of type $S$, the exchange takes place at the average price. If, instead, an agent of type $T$ buys from an agent of type $S$, he does so at the average price minus a discount. The fact that agents of type $T$ can buy and sell at more favorable prices than agents of type $S$ gives them the incentive to become intermediaries. ${ }^{5}$

Lastly, we examine the efficiency of the market equilibrium. When the measure of agents of type $S$ and $T$ is exogenous, efficiency only requires that, every time two agents meet, the property of the asset goes to the one who has the highest valuation. In the equilibrium, every time a low-valuation agent meets a high-valuation agent, the asset goes to the high-valuation agent. Thus, the market equilibrium is efficient.

However, efficiency is not a robust property of the market equilibrium. To see why, note that the equilibrium does not only feature fundamental trades-which are the trades that guaran-

\footnotetext{
${ }^{5}$ The bid-ask spread charged by agents of type $T$ to agents of type $S$ is $\Delta u /\left(r+2 \sigma+\lambda_{S}\right)$, which is increasing in the difference $\Delta u$ in the flow utility between high and low-valuation agents, decreasing in the rate $\sigma$ at which agents' preferences change, and decreasing in the rate $\lambda_{S}$ at which agents of type $S$ get an opportunity to trade with other agents of type $S$.
} 
tee efficiency, as the asset goes from low-valuation to high-valuation agents-but it also features intermediation trades-which are trades that contribute nothing to efficiency, as the asset is exchanged by two agents with the same valuation. Since intermediation trades have no value in terms of efficiency but have positive value to the two agents involved in them, the efficiency of equilibrium will not be robust to small perturbation the environment.

We illustrate the fragility of the efficiency of equilibrium by means of three examples.

1. Transaction cost: Consider a version of the model with transaction costs. In particular, every time the asset is exchanged, the buyer and the seller both incur a cost of $c / 2>0$ units of the numeraire good. The cost $c$ may represent the cost of filling the paperwork required to exchange the ownership of the asset, the cost of physically moving the asset from the seller's location to the buyer's location, etc... In Appendix B.1, we show that, as long as $c$ is not too large, the equilibrium features the same pattern of trade as in Figure 1. Hence, the equilibrium features both fundamental and intermediation trades. This is intuitive, as a small $c$ does not change the sign of the bilateral gains associated with different types of trades. In contrast, efficiency requires the asset being always traded from low to high-valuation agents (i.e. fundamental trades are efficient) and never being traded by agents with the same valuation (i.e. intermediation trades are not efficient). This is also intuitive, as the intermediation trades contribute negatively to efficiency in the presence of a transaction cost. Therefore, as long as $c$ is not too large, the equilibrium is inefficient.

2. Richer preferences: Consider a version of the model in which the flow utility from holding the asset for an agent of type $(i, j)$ is $u_{i, j}$ with $0<u_{S, L}<u_{S, H}, u_{T, L}=u_{S, L}-\varepsilon, u_{T, H}=u_{S, H}+\varepsilon$ and $\varepsilon>0$. In words, agents of type $T$ have more extreme preferences for the asset than agents of type $S$. In Appendix B.2, we show that, as long as $\varepsilon$ is not too large, the equilibrium pattern of trade is the one illustrated in Figure 1. In particular, the equilibrium pattern of trade is such that $(S, L)$ sells to $(T, L)$ and $(T, H)$ sells to $(S, H)$. Intuitively, an agent of type $(S, L)$ sells the asset to an agent of type $(T, L)$ even though he has a higher valuation because the buyer can sell the asset at a higher price to somebody else. Similarly, an agent of type $(T, H)$ sells the asset to an agent of type $(S, H)$ even though he has a higher valuation because he can go back to the market and purchase another unit of the asset at a lower price. Efficiency requires that, in any meeting between two agents, the property of the asset always goes to the one with the highest valuation. In particular, efficiency requires that $(T, L)$ sells to $(S, L)$ and $(S, H)$ sells to $(T, H)$. Hence, the equilibrium pattern of trade is inefficient.

The inefficiency illustrated in the above example arises naturally whenever the set of valuations for the asset is rich enough. In fact, in an environment where an agent's valuation is a continuous variable (as in Hugonnier, Lester and Weill 2016) that may or may not be correlated with his commitment type, there will typically be meetings between an agent of type $S$ with the 
asset and an agent of type $T$ without the asset where the $S$-agent has a higher valuation than the $T$-agent and, yet, the gains from trade are strictly positive because of the difference in their commitment power.

3. Heterogeneity in contact rates: Consider a version of the model in which agents of type $S$ contact trading partners at the rate $\lambda$, while agents of type $T$ contact trading partners at the rate $\omega \lambda$, with $\omega \in(0,1)$. In words, consider a version of the model in which agents of type $T$ have a lower contact rate than agents of type $S$. In Appendix B.3, we show that, as long as $\omega$ is close enough to 1, the equilibrium pattern of trade is the same as in Figure 1. In particular, the equilibrium pattern of trade is such that agents of type $T$ act as intermediaries and agents of type $S$ act as final users. Intuitively, agents of type $T$ act as intermediaries for agents of type $S$ (i.e., $T L$ buys from $S L$ and $T H$ sells to $S H$ ) even though they are less likely to find a trading partner because, if they do so, they can trade at a more favorable price. In contrast, it is easy to show that efficiency requires the agents with the highest contact rate to act as intermediaries and the agents with the lower contact rate to act as final users. Intuitively, efficiency requires agents of type $S$ to act as intermediaries for agents of type $T$ (i.e., $S L$ buys from $T L$ and $S H$ sells to $T H$ ) because this leads to a better allocation of the asset.

\section{Extent and Determinants of Intermediation}

In this section, we characterize the equilibrium measures of agents of type $T$, who act as intermediaries, and of agents of type $S$, who act as final users. We refer to this as the intermediation equilibrium. We assume that, upon entering the market, agents choose whether to invest in a technology that allows them to commit to take-it-or-leave-it offers or not. In Section 4.1, we compute the benefit to an agent from having commitment power, and characterize the set of intermediation equilibria. In Section 4.2, we examine the welfare properties of equilibrium. We find that equilibrium is inefficient whenever there is a positive measure of intermediaries. In Section 4.3, we study the effect of a decline in trading frictions on the extent of intermediation. We find that the intermediation becomes more prevalent as trading frictions become smaller. In Section 4.4, we study the effect of a decline in the interest rate on investments alternative to the commitment technology. We find that intermediation grows as interest rates fall. In order to sidestep issues related to transitional dynamics, we carry out the analysis for $r \rightarrow 0$.

\subsection{Intermediation Equilibrium}

\subsubsection{Cost of Commitment}

We assume that, upon entering the asset market, agents can acquire a technology that gives them the power to commit to take-it-or-leave-it offers and, hence, to become intermediaries. The cost 
of the commitment technology is $c>0$ units of the numeraire good per unit of time.

A couple of comments about the way we model the choice of acquiring commitment power are in order. We model the choice as an investment in a costly technology. This is very abstract, but it does capture several realistic scenarios. For example, an agent may attain commitment power by delegating all of his negotiations to representatives who have no authority over pricing decisions (e.g., hiring a salesperson). Under this view, the cost of commitment are the wages paid to the agent's representatives. An agent may achieve commitment power by making the history of prices at which he transacts public and, by doing so, building a reputation for sticking to take-it-or-leave-it offers. Under this view, the cost of commitment is the price of the resources required to maintain a public record of transactions. It may also be the case that all agents have the ability to commit to take-it-or-leave-it offers, but that they decide to do so only if they understand the mechanics of strategic bargaining. Under this view, the cost of commitment is the cost of taking classes or reading books about the "Art of the Deal." It may even be the case that all agents in the market have the ability to commit to take-it-or-leave-it offers and they all understand the value of doing so. Yet, there might be a social stigma associated with using commitment power. Under this view, the cost of commitment is the disutility of being regarded as a pushy trader. ${ }^{6}$

We assume that every agent faces the same cost $c$ of acquiring commitment power. The assumption simplifies the exposition but is not essential to any of the qualitative results contained in this section. In a previous version of the paper (see Farboodi, Jarosch and Menzio 2016), we generalize these results to the case in which agents are heterogeneous with respect to the cost at which they can acquire commitment power.

\subsubsection{Benefit of Commitment}

The annuitized lifetime utility of an agent without commitment power is

$$
\begin{aligned}
r U_{S, j} & =\lambda_{S}\left(D_{S, H}-D_{S, L}\right) / 4, \\
r V_{S, j} & =\left(u_{H}+u_{L}\right) / 2+\lambda_{S}\left(D_{S, H}-D_{S, L}\right) / 4 .
\end{aligned}
$$

The expression in (4.1) is easy to understand. When his valuation is $L$, an agent of type $S$ without the asset enjoys an expected utility of zero per unit of time. When his valuation is $H$, the agent enjoys an expected utility of $\lambda_{S}\left(D_{S, H}-D_{S, L}\right) / 2$ per unit of time. In the limit for $r \rightarrow 0$, the lifetime utility of the agent is given by the average of his expected utility per unit of time in the two valuation states. The intuition behind (4.2) is analogous.

\footnotetext{
${ }^{6}$ In the 2014 Harris Survey, the occupation ranked lowest by prestige is "real estate broker". The occuptions ranked just above are "union leader" and "stockbroker" (see Harris Poll 2014) These are all occupations that involve some form of intermediation and require negotiation skills.
} 
The annuitized lifetime utility of an agent with commitment power is

$$
\begin{aligned}
& r V_{T, j}=\lambda_{S}\left(D_{S H}-D_{S L}\right) / 2+\lambda_{T}\left(D_{T H}-D_{T L}\right) / 4 \\
& r V_{T, j}=\left(u_{L}+u_{H}\right) / 2+\lambda_{S}\left(D_{S H}-D_{S L}\right) / 2+\lambda_{T}\left(D_{T H}-D_{T L}\right) / 4 .
\end{aligned}
$$

Consider the expression in (4.3). When his valuation is $L$, an agent of type $T$ without the asset enjoys an expected utility of $\lambda_{S}\left(D_{T, L}-D_{S, L}\right)$ per unit of time. When his valuation is $H$, the agent enjoys an expected utility of $\lambda_{S}\left(D_{T, H}-D_{S, L}\right)+\lambda_{T}\left(D_{T, H}-D_{T, L}\right)$ per unit of time. In the limit for $r \rightarrow 0$, the lifetime utility of the agent is the average of his expected utility across the two valuation states. The expression in (4.3) follows from this observation and the fact that $D_{T, H}-D_{S, L}=D_{S, H}-D_{T, L}$. The intuition behind (4.4) is similar.

The benefit of acquiring commitment power, $b$, is given by the difference between the annuitized lifetime utility of an agent of type $T$ and the annuitized lifetime utility of an agent of type $S$ with the same valuation for the asset and the same inventory of the asset. From (4.1)-(4.4), it follows that the benefit of commitment is given by

$$
b=\left[\lambda_{S}\left(D_{S, H}-D_{S, L}\right)+\lambda_{T}\left(D_{T, H}-D_{T, L}\right)\right] / 4
$$

The above expression is easy to understand. The first term on the right-hand side of (4.5) are the additional rents that an agent of type $T$ can extract when trading with agents of type $S$, which is equal to $1 / 4$ of $D_{S, H}-D_{S, L}$. The second term are the additional rents that an agent of type $T$ can extract when trading with other agents of type $T$, which is equal to $1 / 4$ of $D_{T, H}-D_{T, L}$.

Substituting $D_{S, H}-D_{S, L}$ with (3.20) and $D_{T, H}-D_{T, L}$ with (3.21), we can rewrite the benefit of commitment as

$$
b=\left\{\frac{\lambda_{S}}{2 \sigma+\lambda_{S}}+\frac{\lambda_{T}}{2 \sigma+2 \lambda_{S}+\lambda_{T}}\right\} \frac{\Delta u}{4},
$$

where the meeting rates $\lambda_{S}$ and $\lambda_{T}$ are respectively given by

$$
\begin{aligned}
& \lambda_{T}=\lambda \phi_{T} / 4+\sqrt{\sigma^{2}+\lambda \sigma / 2}-\sqrt{\sigma^{2}+\lambda \sigma / 2+\left(\lambda \phi_{T}\right)^{2} / 16}, \\
& \lambda_{S}=\kappa-\lambda \lambda_{T}, \quad \kappa \equiv \sqrt{\sigma^{2}+\lambda \sigma / 2}-\sigma .
\end{aligned}
$$

The function $b\left(\phi_{T}\right)$ implicitly defined by (4.6) and (4.7) has two important properties. First, the benefit of commitment power to an individual is the same whether nobody else has commitment or whether everyone else does, i.e. $b(0)=b(1)$. Second, the benefit of commitment power to an individual is strictly increasing in the measure of agents with commitment for all $\phi_{T}<\phi_{T}^{*}$ and strictly decreasing for all $\phi_{T}>\phi_{T}^{*}$, where $\phi_{T}^{*} \in(0,1)$. Taken together, these two properties imply that the benefit of commitment power to an individual attains its minimum, $\underline{b}$, when $\phi_{T}=\{0,1\}$ and its maximum, $\bar{b}$, when $\phi_{T}=\phi_{T}^{*}$. The properties of $b\left(\phi_{T}\right)$ are illustrated in Figure 2 . 
The above properties of $b\left(\phi_{T}\right)$ are central to understand the equilibrium extent of intermediation and, thus, deserve an explanation. To understand the first property, consider the value of commitment to an individual agent living either in a market populated only by agents of type $S$ or in a market populated only by agents of type $T$. In either scenario, the outside option of the traders contacted by the agent is the same. In the first scenario, the agent contacts agents of type $S$, whose outside option is trading with anybody else and capturing half of the surplus. In the second scenario, the agent contacts agents of type $T$, whose outside option is also trading with anybody else and capturing half of the surplus. Since the trader's outside option is the same in either scenario, the surplus in a meeting between the agent and a trader is also the same. Moreover, in either scenario, the agent captures $50 \%$ more of the surplus by having commitment power. In the first scenario, the agent captures 100 rather than $50 \%$ of the surplus. In the second scenario, the agent captures $50 \%$ rather than none of the surplus. Overall, the benefit to the agent of having commitment power is the same whether nobody else or everybody else has commitment power.

To understand the second property of $b\left(\phi_{T}\right)$, consider the derivative of $b$ with respect to $\phi_{T}$

$$
\begin{aligned}
b^{\prime}\left(\phi_{T}\right)= & \left\{\left(\frac{1}{2 \sigma+2 \lambda_{S}+\lambda_{T}}-\frac{1}{2 \sigma+\lambda_{S}}\right)\right. \\
& \left.+\frac{\lambda_{S}}{\left(2 \sigma+\lambda_{S}\right)^{2}}+\frac{\lambda_{T}}{\left(2 \sigma+2 \lambda_{S}+\lambda_{T}\right)^{2}}\right\} \frac{\Delta u}{4} \cdot \frac{\partial \lambda_{T}}{\partial \phi_{T}}
\end{aligned}
$$

where $\partial \lambda_{T} / \partial \phi_{T}>0$. The first term on the right-hand side of (4.8) is a composition effect. It captures the effect of $\phi_{T}$ on the value of commitment to an individual agent through the increase in the probability that the agent meets a trader of type $T$ and by the decline in the probability that the agent meets a trader of type $S$. This effect is always negative, as traders of type $T$ have a better outside option than traders of type $S$ and fewer rents can be extracted from them. The second and third terms on the right-hand side of (4.8) are price effects. They capture the effect of $\phi_{T}$ on the value of commitment to an individual agent through the change in the outside option of the traders with whom the agent comes into contact. This effect is always positive, as an increase in the fraction people of type $T$ lowers the outside option of all types of traders and increases the rents that can be extracted from them.

When $\phi_{T}$ is small, the price effect dominates and $b^{\prime}\left(\phi_{T}\right)$ is strictly positive. This is so because the outside option of traders of type $S$ is relatively close to the outside option of traders of type $T$ and, hence, the change in the composition of traders has a small effect on the value of commitment. In contrast, when $\phi_{T}$ is high, the composition effects dominates and $b^{\prime}\left(\phi_{T}\right)$ is strictly negative. Intuitively, this is so because the outside option of traders of type $S$ is much smaller than the outside option of traders of type $T$ and, hence, a change in the composition of traders has a large effect on the value of commitment. 


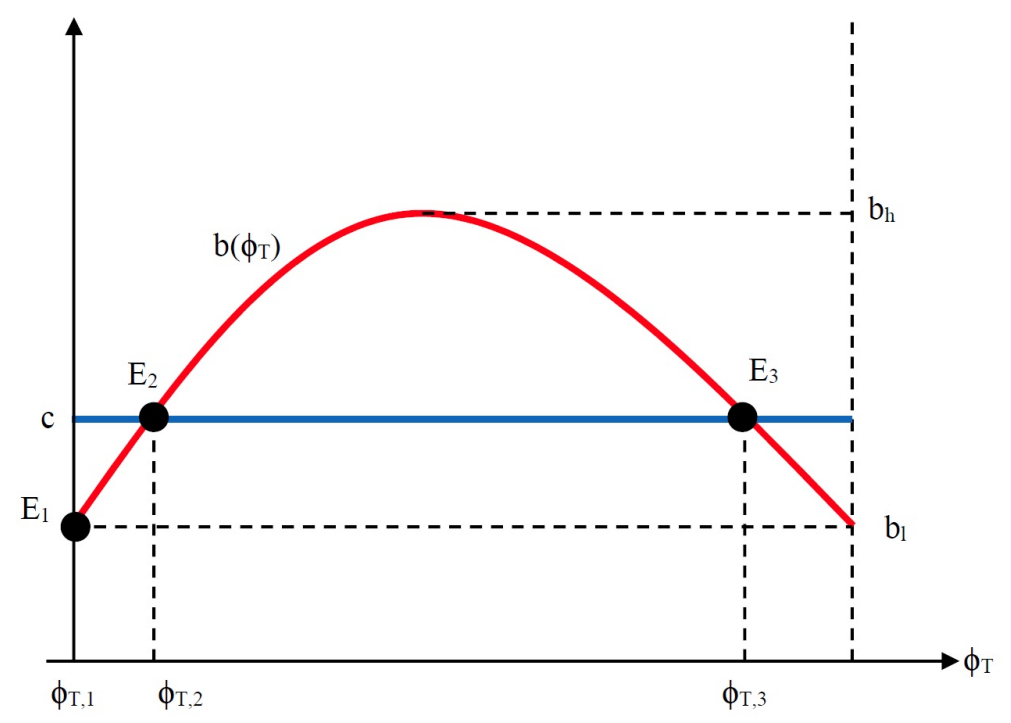

Figure 2: Equilibrium Intermediation

\subsection{Intermediation Equilibrium}

We are now in the position to define an equilibrium for the measure of intermediaries operating in the market.

Definition 3 An Intermediation Equilibrium is a measure $\phi_{T}$ of agents of type $T$ such that: (i) $b\left(\phi_{T}\right)=c$ if $\phi_{T} \in(0,1)$; (ii) $b(1) \geq c$ if $\phi_{T}=1$; (iii) $b(0) \leq c$ if $\phi_{T}=0$.

The characterization of the set of equilibria is illustrated in Figure 2. If the cost $c$ of acquiring commitment power is in the interval $(\underline{b}, \bar{b})$, there exist three equilibria which differ with respect to the extent of intermediation. In the first equilibrium (market as $E_{1}$ in Figure 2), the measure of agents with commitment power is $\phi_{T, 1}=0$. In this equilibrium, there is no intermediation. In the second equilibrium (marked as $E_{2}$ ), the measure of agents with commitment power is $\phi_{T, 2} \in(0,1)$. In this equilibrium, there is a relatively small measure of agents who act as intermediaries and a relatively large measure of agents who act as final users. In the third equilibrium (marked as $E_{3}$ ), the measure of agents with commitment power is $\phi_{T, 3} \in\left(\phi_{T, 2}, 1\right)$. In this equilibrium, there is a relatively large measure of agents who act as intermediaries and a relatively small measure of agents who act as final users. If the cost $c$ of acquiring commitment power is greater than $\bar{b}$, the unique equilibrium is such that $\phi_{T}=0$. In this equilibrium, there is no intermediation. Conversely, if $c$ is smaller than $\underline{b}$, the unique equilibrium is such that $\phi_{T}=1$. In this equilibrium, everyone acts as an intermediary.

For intermediate values of the cost of commitment, there exist three equilibria. However, only two of them are stable. In fact, using the standard heuristic definition of a stable equilibrium as one in which the cost of acquiring commitment power is lower (higher) than the 
benefit in a left (right) neighborhood of equilibrium, only the equilibria $E_{1}$ and $E_{3}$ are stable. The equilibrium $E_{2}$ is an unstable one, as the benefit of commitment exceeds the cost in a right neighborhood of $E_{2}$.

The multiplicity of stable equilibria is caused by the fact that the benefit of commitment is hump-shaped in the measure of intermediaries expected to be in the market. In fact, if an agent expects nobody to become an intermediary, his benefit from acquiring commitment power is lower than the cost, as he expects the outside option of final users to be relatively strong. For this reason, the agent will find it optimal not to become an intermediary, thus rationalizing his expectation. If, on the other hand, an agent expects a measure $\phi_{T, 3}$ of agents to become intermediaries, his benefit from acquiring commitment power is equal to the cost, as he expects the outside option of final users to be relatively weak. For this reason, the agent will be willing to become an intermediary with probability $\phi_{T, 3}$, thus rationalizing his expectation.

The above discussion is summarized by the following proposition.

\section{Proposition 4 Existence and Multiplicity of Intermediation Equilibria.}

(i) For any cost of commitment $c \in(\underline{b}, \bar{b})$, there exist two stable intermediation equilibria with, respectively, $\phi_{T}=0$ and $\phi_{T} \in(0,1)$.

(ii) For any $c>\bar{b}$, there exists a unique stable intermediation equilibrium with $\phi_{T}=0$.

(iii) For any $c<\underline{b}$, there exists a unique stable intermediation equilibrium with $\phi_{T}=1$.

Now, we turn to examine the welfare properties of equilibrium. We measure welfare as the sum of the flow payoffs of all agents. Then welfare in an intermediation equilibrium $\phi_{T}$ is

$$
W\left(\phi_{T}\right)=\left(\mu_{S, L}+\mu_{T, L}\right) u_{L}+\left(\mu_{S, H}+\mu_{T, H}\right) u_{H}-c \phi_{T}
$$

where $\mu_{S, L}, \mu_{T, L}, \mu_{S, H}$ and $\mu_{T, H}$ are given as in (3.23)-(3.26). The first term in (4.9) is the sum of flow utilities for the measure $\mu_{S, L}+\mu_{T, L}$ of low-valuation agents with the asset. The second term is the sum of flow utilities for the measure $\mu_{S, H}+\mu_{T, H}$ of high-valuation agents with the asset. The third term is the sum of flow costs borne by the measure $\phi_{T}$ of agents to acquire the commitment technology and become intermediaries.

Substituting $\mu_{S, L}, \mu_{T, L}, \mu_{S, H}$ and $\mu_{T, H}$ with (3.23)-(3.26), we can rewrite (4.9) as

$$
W\left(\phi_{T}\right)=\frac{u_{H}}{2}-\left[\sqrt{\frac{\sigma^{2}}{\lambda^{2}}+\frac{\sigma}{2 \lambda}}-\frac{\sigma}{\lambda}\right] \Delta u-c \phi_{T} .
$$

The expression in (4.10) reveals that the measures of low and high-valuation agents with the asset and, hence, the sum of their flow utilities is independent of the measure $\phi_{T}$ of intermediaries in the market. In contrast, the sum of flow costs paid to acquire the commitment technology is increasing in the measure $\phi_{T}$ of intermediaries in the market. These findings are intuitive. The 
measure of intermediaries in the market affects the rate at which the asset moves between agents with the same valuation, but has no effect on the rate at which the asset moves between agents with different valuations. Thus, the measure of intermediaries has no impact on the distribution of the asset between low and high-valuation agents. In contrast, the measure of intermediaries affects the amount of resources that are spent on acquiring the commitment technology.

When the measure of agents of type $S$ and $T$ is endogenous, efficiency requires that: (i) every time two agents meet, the property of the asset goes to the one with the highest valuation; (ii) the measure of agents who acquire commitment power is zero. The first condition for efficiency has been discussed in the previous section. The second condition for efficiency is obvious, since acquiring commitment power is costly but has no effect on the asset allocations that are feasible. Taken together, the two conditions imply that, in any efficient allocation, the sum of flow payoffs is

$$
W^{*}=\frac{u_{H}}{2}-\left[\sqrt{\frac{\sigma^{2}}{\lambda^{2}}+\frac{\sigma}{2 \lambda}}-\frac{\sigma}{\lambda}\right] \Delta u .
$$

From (4.10) and (4.11), two results immediately follow. First, whenever there are multiple intermediation equilibria, they can be welfare-ranked according to the measure of intermediaries operating in the market. Specifically, the equilibrium with the lowest measure of intermediaries has the highest welfare, the equilibrium with the second lowest measure of intermediaries has the second highest welfare, etc.... Second, any equilibrium in which there is a positive measure of intermediaries is inefficient.

The above results on the welfare properties of the intermediation equilibrium are summarized in the following proposition.

\section{Proposition 5 Welfare Properties of Intermediation Equilibrium.}

(i) Let $\left\{\phi_{T, 1}, \phi_{T, 2}, \phi_{T, 3}\right\}$ be intermediation equilibria with $\phi_{T, 1}<\phi_{T, 2}<\phi_{T, 3}$. The welfare associated with these equilibria is such that $W\left(\phi_{T, 1}\right)>W\left(\phi_{T, 2}\right)>W\left(\phi_{T, 3}\right)$.

(ii) Let $\phi_{T}$ be an intermediation equilibrium. The welfare $W\left(\phi_{T}\right)$ associated with the equilibrium is equal to the welfare $W^{*}$ associated with the efficient allocation iff $\phi_{T}=0$.

The fact that any equilibrium with intermediation is inefficient is one of our main results. When intermediation is a pure rent-extraction activity, the presence of intermediaries in the market does not lead to any improvements in the asset allocation. Indeed, in the previous section, we brought up several examples in which the presence of intermediaries in the market leads to a worsening of the asset allocation. Whether intermediaries leave the asset allocation unchanged or worsen it, they do extract some rents from final users. In equilibrium, intermediaries dissipate these rents through costly investment in the commitment technology. Therefore, 
when intermediation is a rent-extraction activity, any amount of intermediation is a source of inefficiency.

\subsection{Trading Frictions and Intermediation}

We now want to examine the effect of a decline in trading frictions, modeled as an increase in $\lambda$, on the extent of rent-extraction intermediation. This exercise is interesting for both theoretical and empirical reasons. Theoretically, the exercise is interesting because it is natural to wonder whether rent-extraction intermediation tends to disappear on its own as trading frictions become smaller and markets become more competitive. Empirically, the exercise is interesting because recent progress in Information Technology must have lowered trading frictions. To keep the notation light, we carry out the exercise under the assumption that $\sigma=1$, which is without loss in generality as all the equilibrium objects depend only on the ratio $\lambda / \sigma$ and not on $\lambda$ and $\sigma$ separately.

The effect of an increase in $\lambda$ on the rate $\lambda_{S}=\lambda \mu_{S, L}$ at which an agent meets a mismatched trader of type $S$ is

$$
\frac{\partial \lambda_{S}}{\partial \lambda}=\frac{1 / 2+\lambda \phi_{T}^{2} / 8}{2 \sqrt{1+\lambda / 2+\left(\lambda \phi_{T}\right)^{2} / 16}}-\frac{\phi_{T}}{4}>0 .
$$

An increase in $\lambda$ has two countervailing effects on $\lambda_{S}$. On the one hand, an increase in $\lambda$ tends to increase $\lambda_{S}$ because it increases the rate at which an agent meets a trader. On the other hand, an increase in $\lambda$ tends to lower $\lambda_{S}$ because it reduces the measure $\mu_{S, L}$ of traders of type $S$ who are mismatched. It is easy to check that (4.12) is strictly positive, meaning that the first effect dominates the second one.

The effect of an increase in $\lambda$ on the rate $\lambda_{T}=\lambda \mu_{T, L}$ at which an agent meets a mismatched trader of type $T$ is

$$
\frac{\partial \lambda_{T}}{\partial \lambda}=\frac{\phi_{T}}{4}+\frac{1}{4 \sqrt{1+\lambda / 2}}-\frac{1 / 4+\lambda \phi_{T}^{2} / 16}{\sqrt{1+\lambda / 2+\left(\lambda \phi_{T}\right)^{2} / 16}}>0 .
$$

An increase in $\lambda$ has also two countervailing effects on $\lambda_{T}$. An increase in $\lambda$ tends to increase $\lambda_{T}$ because it increases the rate at which an agent meets a trader, and it tends to lower $\lambda_{T}$ because it reduces the measure $\mu_{T, L}$ of mismatched traders of type $T$. Again, it is easy to check that (4.13) is strictly positive, meaning that the first effect dominates the second one.

The effect of an increase in $\lambda$ on the benefit $b\left(\phi_{T}\right)$ of acquiring commitment power is

$$
\begin{aligned}
\frac{\partial b\left(\phi_{T}\right)}{\partial \lambda} & =\left[\frac{1}{2+\lambda_{S}}-\frac{\lambda_{S}}{\left(2+\lambda_{S}\right)^{2}}\right] \frac{\partial \lambda_{S}}{\partial \lambda} \frac{\Delta u}{4} \\
& +\left[\frac{1}{2+2 \lambda_{S}+\lambda_{T}} \frac{\partial \lambda_{T}}{\partial \lambda}-\frac{\lambda_{T}}{\left(2+2 \lambda_{S}+\lambda_{T}\right)^{2}}\left(2 \frac{\partial \lambda_{S}}{\partial \lambda}+\frac{\partial \lambda_{T}}{\partial \lambda}\right)\right] \frac{\Delta u}{4}
\end{aligned}
$$


The first line on the right-hand side of (4.14) measures the impact of an increase in $\lambda$ on the additional rents that an agent can capture from traders of type $S$ by having commitment power. The impact is given by the sum of two effects: a volume effect and a margin effect. The volume effect is positive, as an increase in $\lambda$ raises the rate $\lambda_{S}$ at which the agent meets a mismatched trader of type $S$. The margin effect is negative, as an increase in $\lambda$ improves the outside option of a mismatched trader of type $S$ and, thus, shrinks the additional rents $\Delta u /\left[4\left(2+\lambda_{S}\right)\right]$ that the agent can capture from him by having commitment power. It is immediate to see that the sign of the first line is positive, meaning that the volume effect dominates. Intuitively, this is because, while the rate at which an agent meets a mismatched $S$-trader is proportional to $\lambda_{S}$, the additional rents that an agent can extract are proportional to $1 /\left(2+\lambda_{S}\right)$, where the 2 represents the discounting effect of preference changes on the overall gains from trade. The second line on the right-hand side of (4.14) is the impact of an increase in $\lambda$ on the additional rents that an agent can capture from traders of type $T$ by having commitment power. Also in this case, the impact can be decomposed into a volume and a margin effect. And, also in this case, the volume effect dominates so that the second line is postive. From these observations, it follows that an increase in $\lambda$ unambiguously increases the benefit of commitment power.

We are now in the position to analyze the effect of a decline in trading frictions on the extent of rent-extraction intermediation. To this aim, consider Figure 3(a) which depicts the case in which, for $\lambda=\lambda_{0}$, the cost of commitment $c$ is in the interval $(\underline{b}, \bar{b})$ so that there are exist two stable equilibrium levels of intermediation $\phi_{T, 1}$ and $\phi_{T, 3}$ with $0=\phi_{T, 1}<\phi_{T, 3}<1$. An increase in the meeting rate from $\lambda_{0}$ to $\lambda_{1}$ leads to an increase in the benefit of commitment for all $\phi_{T}$ and, in turn, to an increase in the equilibrium levels of intermediation. If the increase in $\lambda$ is small enough, then the stable equilibrium levels of intermediation become $\phi_{T, 1}^{\prime}$ and $\phi_{T, 3}^{\prime}$ with $\phi_{T, 1}^{\prime}=\phi_{T, 1}=0$ and $\phi_{T, 3}^{\prime}>\phi_{T, 3}$. Otherwise, the stable equilibrium level of intermediation becomes $\phi_{T}^{\prime}=1>\phi_{T, 3}$. In either case, a decline in trading frictions leads to an increase in the extent of rent-extraction intermediation. The same conclusions apply to the cases in which $c>\bar{b}$ or $c<\underline{b}$.

We have thus established the following proposition.

Proposition 6 Trading Frictions and Intermediation. Let $\left\{\phi_{T, i}\right\}$ be the intermediation equilibria given $\lambda_{0}$, with $\phi_{T, 1}<\ldots<\phi_{T, N}$. Let $\left\{\phi_{T, i}^{\prime}\right\}$ be the intermediation equilibria given $\lambda_{1}>\lambda_{0}$, with $\phi_{T, 1}^{\prime}<\ldots<\phi_{T, N^{\prime}}^{\prime}$. Then $\left\{\phi_{T, i}^{\prime}\right\}$ is greater than $\left\{\phi_{T, i}\right\}$, in the sense that $\phi_{T, 1}^{\prime} \geq \phi_{T, 1}$ and $\phi_{T, N^{\prime}}^{\prime} \geq \phi_{T, N}$.

Proposition 6 is surprising from the point of view of theory. After all, the following argument appears to be correct: As frictions decline, final users can locate trading partners more rapidly and, hence, the surplus that intermediaries can capture from them become smaller. As 


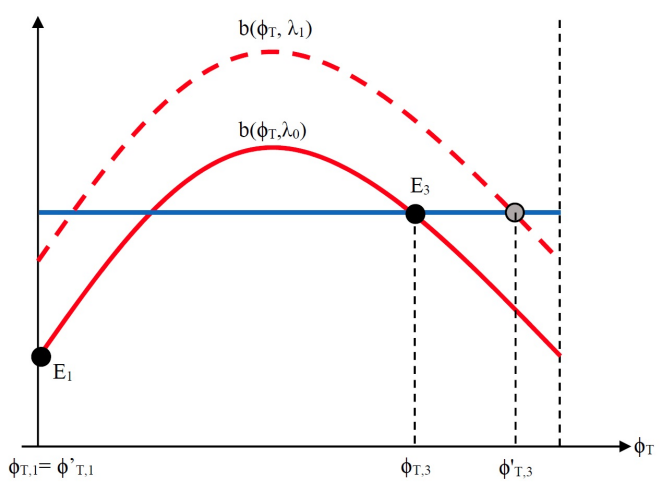

(a) Trading Frictions

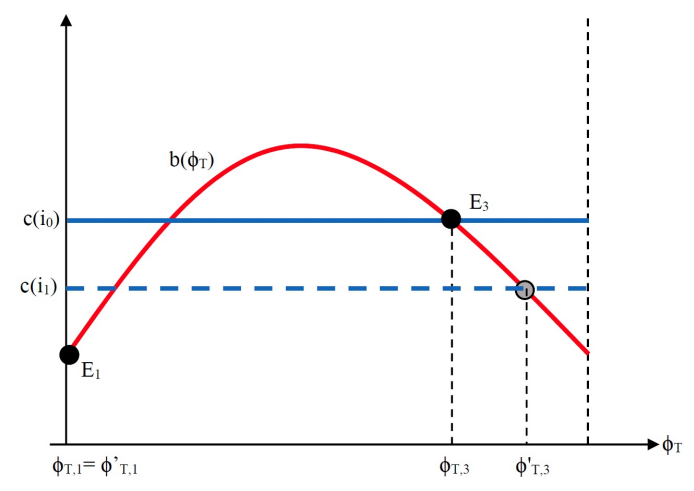

(b) Interest Rates

Figure 3: Comparative Statics on Equilibrium Intermediation

the rents that intermediaries can capture become smaller, fewer of them come into the market. However, this argument is incomplete because, as frictions become smaller, not only does the surplus that intermediaries can capture from final users becomes smaller but the frequency at which intermediaries encounter final users becomes larger. And, since this other effect dominates, more and more intermediaries come into the market as frictions become smaller.

Proposition 6 is interesting from an empirical point of view. Some readers may think that our theory is not relevant because "In this day and age, trading frictions are very small". Yet, Proposition 6 implies that rent-extraction intermediation is not a phenomenon that vanishes when trading frictions get smaller and smaller. To the contrary, Proposition 6 implies that rent-extraction intermediation is a phenomenon that becomes more and more relevant when trading frictions become smaller. Indeed, Proposition 6 suggests the possibility that the decline in trading frictions caused by the improvements in Information Technology may be one of the reasons for the dramatic rise in the financial intermediation sector that has taken place in the US since the 1950s (see, e.g., Philippon 2015).

The next natural step is to examine the effect of an increase in $\lambda$ on welfare. From (4.10) and Proposition 6 it immediately follows that an increase in $\lambda$ has two opposing effects on welfare. On the one hand, an increase in $\lambda$ leads to a better allocation of the asset, in the sense that it increases the measure of high-valuation agents with the asset and it reduces the measure of low-valuation agents with the asset. On the other hand, an increase in $\lambda$ leads to an increase in the measure of intermediaries and, in turn, to an increase in the amount of resources that are spent on the commitment technology.

In order to understand which effect dominates, it is useful to start from the observation that welfare-which we defined as the average flow payoffs among all market participants-is also 
equal to the average annuitized lifetime utilities among all market participants. ${ }^{7}$ That is, $W\left(\phi_{T}\right)$ is equal to $r \sum_{i, j}\left[\mu_{i, j} U_{i, j}+v_{i, j} V_{i, j}\right]-c \phi_{T}$. Then, using (4.1)-(4.4) to substitute out $U_{i, j}$ and $V_{i, j}$, we can write welfare as

$$
W\left(\phi_{T}\right)= \begin{cases}\frac{\sqrt{1+\lambda / 2}-1}{\sqrt{1+\lambda / 2}+1} \frac{\Delta u}{4}+\frac{u_{L}+u_{H}}{4}, & \text { if } \phi_{T}=0, \\ \frac{\sqrt{1+\lambda / 2}-1}{\sqrt{1+\lambda / 2}+1} \frac{\Delta u}{4}+\frac{u_{L}+u_{H}}{4}-c, & \text { if } \phi_{T}=1, \\ \frac{\lambda_{S}}{2+\lambda_{S}} \frac{\Delta u}{4}+\frac{u_{L}+u_{H}}{4}, & \text { if } \phi_{T} \in(0,1) .\end{cases}
$$

The first line on the right-hand side of (4.15) makes use of the fact that $\lambda_{S}$ is equal to $(1+$ $\lambda / 2)^{1 / 2}-1$ in any intermediation equilibrium with $\phi_{T}=0$. The second line makes use of the fact that $\lambda_{T}$ is equal to $(1+\lambda / 2)^{1 / 2}-1$ in any intermediation equilibrium with $\phi_{T}=1$. The third line makes use of the fact that, in any intermediation equilibrium with $\phi_{T} \in(0,1)$, the cost of commitment $c$ must be equal to the benefit of commitment $b\left(\phi_{T}\right)$.

In an intermediation equilibrium with $\phi_{T}=0$, which exists when either $c>\bar{b}$ or $c \in(\underline{b}, \bar{b})$, a (small) increase in $\lambda$ unambiguously increases welfare. Similarly, in an intermediation equilibrium with $\phi_{T}=1$, which exists when $c<\underline{b}$, an increase in $\lambda$ leads to higher welfare. These findings are intuitive. In the intermediation equilibria with $\phi_{T} \in\{0,1\}$, a (small) increase in $\lambda$ improves the allocation of the asset but does not induce any additional entry of intermediaries and, hence, it does not lead to an additional resources being wasted in the commitment technology.

Now, consider an intermediation equilibrium with $\phi_{T} \in(0,1)$, which exists when $c \in(\underline{b}, \bar{b})$. In this equilibrium, the rate $\lambda_{S}$ at which an agent meets a mismatched trader of type $S$ is such that the cost and benefit of commitment are equalized, i.e.

$$
c=\left[\frac{\lambda_{S}}{2+\lambda_{S}}+\frac{\sqrt{1+\lambda / 2}-1-\lambda_{S}}{\sqrt{1+\lambda / 2}+1+\lambda_{S}}\right] \frac{\Delta u}{4} .
$$

A stable intermediation equilibrium is associated with the smallest root of (4.16), whereas an unstable equilibrium is associated with the largest root of (4.16). The right-hand side of (4.16) is a concave function of $\lambda_{S}$ and it is strictly increasing in $\lambda$. Thus, the smallest root of (4.16) is decreasing in $\lambda$. This means that an increase in $\lambda$ lowers the value of $\lambda_{S}$ at a stable intermediation equilibrium with $\phi_{T} \in(0,1)$. It then follows from (4.15) that an increase in $\lambda$ unambiguously lowers welfare at a stable intermediation equilibrium with $\phi_{T} \in(0,1)$.

The above observations together with the monotonicity of the $b\left(\phi_{T}\right)$ with respect to $\lambda$ lead us to the following proposition.

\footnotetext{
${ }^{7}$ All details are available upon request.
} 
Proposition 7 Trading Frictions and Welfare. For any $c>0$, there exists $\lambda_{1}$ and $\lambda_{2}$ with $0<\lambda_{1}<\lambda_{2} \leq \infty$ such that:

(i) For $\lambda<\lambda_{1}$, there is a unique stable intermediation equilibrium with $\phi_{T}=0$. At this equilibrium welfare increases in $\lambda$.

(ii) For $\lambda \in\left(\lambda_{1}, \lambda_{2}\right)$, there are two stable equilibria with $\phi_{T, 1}=0$ and $\phi_{T, 3} \in(0,1)$. Welfare increases in $\lambda$ at the first equilibrium, and decreases at the second equilibrium.

(iii) For $\lambda>\lambda_{2}$, there is a unique stable equilibrium with $\phi_{T}=1$. At this equilibrium welfare increases in $\lambda$.

Proposition 7 states that, if the fraction of rent-extraction intermediaries in the market is interior, welfare falls as trading frictions become smaller. This finding is surprising and it is useful to provide some intuition for it. As $\lambda \rightarrow \lambda_{2}$, the fraction of intermediaries at the interior equilibrium converges to 1 . When $\phi_{T} \rightarrow 1$, agents of type $S$ never capture any of the gains from trade and, hence, their lifetime utility converges to its autarky level. Since agents of type $T$ have the same lifetime utility as agents of type $S$ after taking into account the resources they spent on the commitment technology, it follows that equilibrium welfare converges to welfare in autarky. In contrast, for any $\lambda \in\left(\lambda_{1}, \lambda_{2}\right)$, agents of type $S$ are strictly better off than in autarky and, hence, so are agents of type $T$. Therefore, for any $\lambda \in\left(\lambda_{1}, \lambda_{2}\right)$, welfare is strictly higher than in autarky.

\subsection{Interest Rates and Intermediation}

We conclude by examining the effect on rent-extraction intermediation of a decline in the interest rate on investments that are alternative to the investment in the commitment technology. To carry out the exercise, we assume that there exists a continuous function $c(i)$ mapping the interest rate $i \geq 0$ on alternative investments on the opportunity cost of acquiring commitment power, with $c(0)=0$ and $c^{\prime}(i)>\varepsilon>0$ for all $i \geq 0$.

Figure 3(b) illustrates the situation in which the interest rate $i_{0}$ is such that the opportunity cost of the commitment technology $c\left(i_{0}\right)$ is in the interval $(\underline{b}, \bar{b})$ so that there are two stable equilibrium levels of intermediation $\phi_{T, 1}$ and $\phi_{T, 3}$ with $0=\phi_{T, 1}<\phi_{T, 3}<1$. If the decline in the interest rate from $i_{0}$ to $i_{1}$ is small enough, then the stable equilibrium levels of intermediation become $\phi_{T, 1}^{\prime}$ and $\phi_{T, 3}^{\prime}$ with $\phi_{T, 1}^{\prime}=\phi_{T, 1}$ and $\phi_{T, 3}^{\prime}>\phi_{T, 3}$. Otherwise, the stable equilibrium level of intermediation becomes $\phi_{T}^{\prime}=1>\phi_{T, 3}$. In either case, a decline in the interest rate leads to an increase in the extent of rent-extraction intermediation. The same conclusion also applies to the situations in which the interest $i_{0}$ is such that $c\left(i_{0}\right)>\bar{b}$ or $c\left(i_{0}\right)<\underline{b}$.

Proposition 8 Interest Rates and Intermediation. Let $\left\{\phi_{T, i}\right\}$ be the intermediation equilibria given $i_{0}$, with $\phi_{T, 1}<\ldots<\phi_{T, N}$. Let $\left\{\phi_{T, i}^{\prime}\right\}$ be the intermediation equilibria given $i_{1}<i_{0}$, 
with $\phi_{T, 1}^{\prime}<\ldots<\phi_{T, N^{\prime}}^{\prime}$. Then $\left\{\phi_{T, i}^{\prime}\right\}$ is greater than $\left\{\phi_{T, i}\right\}$, in the sense that $\phi_{T, 1}^{\prime} \geq \phi_{T, 1}$ and $\phi_{T, N^{\prime}}^{\prime} \geq \phi_{T, N}$

Next, we want to understand the effect of a decline in the interest rate $i$ on welfare. From (4.10) and Proposition 8 it follows that a decline in $i$ has two countervailing effects on welfare. On the one hand, a decline in $i$ leads to a decline in the opportunity cost of the resources devoted by intermediaries to acquire the commitment technology. On the other hand, a decline in $i$ leads to an increase in the measure of agents who decide to become intermediaries and, for this reason, devote resources to acquire the commitment technology.

In order to figure out which effect dominates, it is sufficient to return to the formula for welfare in (4.15). In an equilibrium with $\phi_{T}=0$, which exists when either $c(i)>\bar{b}$ or $c(i) \in$ $(\underline{b}, \bar{b})$, a decline in $i$ unambiguously increases welfare. This is because, a decline in $i$ lowers the opportunity cost of acquiring the commitment technology needed to intermediate without inducing any additional entry of intermediaries. For the same reason, in an equilibrium with $\phi_{T}=1$, which exists when $c(i)<\underline{b}$, a decline in $i$ leads to higher welfare.

In an intermediation equilibrium with $\phi_{T} \in(0,1)$, which exists when $c(i) \in(\underline{b}, \bar{b})$, the rate $\lambda_{S}$ at which an agent meets a mismatched trader of type $S$ is such that the cost and benefit of commitment are equalized, i.e.

$$
c(i)=\left[\frac{\lambda_{S}}{2+\lambda_{S}}+\frac{\sqrt{1+\lambda / 2}-1-\lambda_{S}}{\sqrt{1+\lambda / 2}+1+\lambda_{S}}\right] \frac{\Delta u}{4} .
$$

A stable intermediation equilibrium is associated with the smallest root of (4.17). The righthand side of (4.17) is concave in $\lambda_{S}$ and the left-hand side of (4.17) is increasing in $i$. Thus, the smallest root of (4.17) is increasing in $i$. This means that a decline in $i$ lowers the value of $\lambda_{S}$ at a stable intermediation equilibrium with $\phi_{T} \in(0,1)$. It then follows from (4.15) that a decline in $i$ unambiguously lowers welfare at a stable intermediation equilibrium with $\phi_{T} \in(0,1)$.

The above observations together with the assumptions about the function $c(i)$ immediately imply the following.

Proposition 9 Interest Rates and Welfare. There exists $i_{1}$ and $i_{2}$ with $0<i_{1}<i_{2}$ such that:

(i) For $i>i_{2}$, there is a unique stable intermediation equilibrium with $\phi_{T}=0$. At this equilibrium, a decline in i increases welfare.

(ii) For $i \in\left(i_{1}, i_{2}\right)$, there are two stable equilibria with $\phi_{T, 1}=0$ and $\phi_{T, 3} \in(0,1)$. A decline in $i$ increases welfare at the first equilibrium, and lowers welfare at the second equilibrium.

(iii) For $i<i_{1}$, there is a unique stable equilibrium with $\phi_{T}=1$. At this equilibrium, a decline in i increases welfare. 
Proposition 8 states that the extent of rent-extraction intermediation grows when interest rates fall, and shrinks when interest rates rise. This is intuitive. When interest rates fall, agents face a lower opportunity cost of investing in the commitment technology-e.g., hiring a sales team, learning about effective bargaining techniques, or suffering the social stigma associated with being a tough trader-and for this reason more of them acquire commitment and engage in rent-extraction intermediation. Proposition 9 states that, if the fraction of rent-extraction intermediaries in the market is positive but less than one, the total welfare of the agents in the market declines when interest rates fall. This result is easy to understand when we think of welfare as the sum of the lifetime utilities of agents of type $S$ and $T$. A decline in $i$ leads to an increase in the measure of agents of type $T$, which unambiguously lowers the lifetime utility of agents of type $S$. Since agents of type $T$ have, ex-ante, the same lifetime utility as agents of type $S$, total welfare must decline.

The findings in Propositions 8 and 9 are closely related to the hypothesis of "reaching for yield" formulated by Rajan (2006). According to this hypothesis, when the return on safe assets falls, investors rebalance their portfolios towards alternative assets with a higher return and risk. ${ }^{8}$ If investors do not fully internalize the downside risk of the alternative assets, their portfolio rebalancing is socially undesirable. Here, we highlight a different channel through which low interest rates also lead to socially undesirable behavior by investors. Namely, low interest rates lead investors to reallocate their resources away from productive investments and towards investments that allow them to capture a larger share of the gains from trade.

\section{Transaction Tax}

In this section, we study the effect of introducing a transaction tax. We assume that, every time a transaction takes place, the government collects a tax $\tau \geq 0$ from the buyer-seller pair. The government redistributes the tax revenues to all market participants in the form of a lump sum. In Section 5.1, we study the effect of the transaction tax on the market equilibrium. We find that, depending on the size of the tax, the pattern of trade and the allocation of the asset varies. In Section 5.2, we study the effect of the transaction tax on the intermediation equilibrium. We find that the introduction of the transaction tax lowers the equilibrium measure of intermediaries in the market. In Section 5.3, we identify the welfare-maximizing transaction tax. We find that the optimal tax has a simple formula and that it is sufficient to restore efficiency.

\subsection{Market Equilibrium}

Here, we study the effect of the transaction tax on the market equilibrium.

\footnotetext{
${ }^{8}$ See Cociuba, Shukayev and Ueberfeldt (2016) for an overview of the literature on the "reaching for yield" hypothesis. See Jimenez et al. (2014) for some empirical evidence supporting this hypothesis.
} 


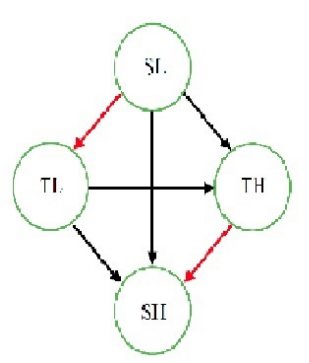

(a)

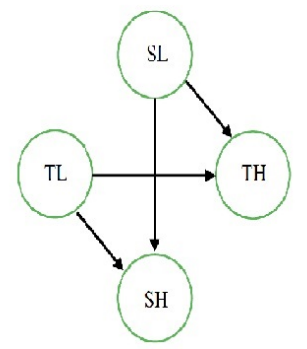

(b)

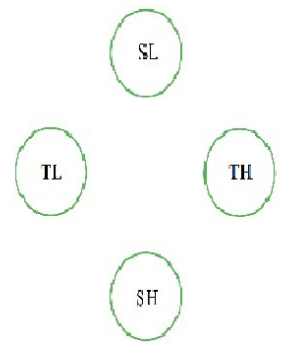

(c)

Notes: Panel (a): pattern of trade in equilibrium with intermediation. Panel (b): pattern of trade in equilibrium without intermediation. Panel (c): pattern of trade in equilibrium without trade.

Figure 4: Patterns of Trade with Transaction Tax

\subsubsection{Market Equilibrium with Intermediation}

We start by looking for conditions on the transaction tax $\tau$ under which there is a market equilibrium with the same pattern of trade as in Figure 1, which we reproduced for the convenience of our readers in Figure 4(a). We refer to this type of equilibrium as an equilibrium with intermediation as it features not only fundamental trades-i.e., the trades in which the asset moves from low to high-valuation agents-but also intermediation trades-i.e., the trades in which an agent of type $T$ trades with an agent of type $S$ with the same valuation.

In a market equilibrium with intermediation trade, the after-tax gains from trade between an agent of type $(S, H)$ without the asset and an agent of type $(S, L)$ with the asset are

$$
D_{S, H}-D_{S, L}-\tau=\frac{\Delta u-2 \sigma \tau}{2 \sigma+\lambda_{S}}
$$

The after-tax gains from trade between an agent of type $(T, H)$ without the asset and an agent of type $(T, L)$ with the asset are

$$
D_{T, H}-D_{T, L}-\tau=\frac{\Delta u-\left(2 \sigma+2 \lambda_{S}\right) \tau}{2 \sigma+2 \lambda_{S}+\lambda_{T}}
$$

The after-tax gains from trade between an agent of type $(T, L)$ without the asset and an agent of type $(S, L)$ with the asset are

$$
D_{T, L}-D_{S, L}-\tau=\frac{\lambda_{S}\left(D_{S, H}-D_{S, L}-\tau\right)+\lambda_{T}\left(D_{T, H}-D_{T, L}-\tau\right)}{2\left(2 \sigma+2 \lambda_{S}\right)}-\frac{2 \sigma+\lambda_{S}}{2 \sigma+2 \lambda_{S}} \tau
$$

The after-tax gains from trade $D_{S, H}-D_{T, H}-\tau$ between an agent of type $(S, H)$ without the asset and an agent of type $(T, L)$ with the asset are equal to those in (5.3).

The pattern of trade in a market equilibrium with intermediation is individually rational if and only if the after-tax gains from trade are positive in every meeting where trade is supposed 
to take place, and strictly negative in every meeting where trade is supposed not to take place. ${ }^{9}$ It is immediate to see that all of the conditions under which the pattern of trade is individually rational are satisfied if and only if (5.1)-(5.3) are positive. In turn, a bit of algebra reveals that (5.1)-(5.3) are positive iff

$$
\tau \leq \tau_{2} \equiv \frac{\left(\lambda_{S}+\lambda_{T}\right) \Delta u}{2 \sigma\left(\lambda_{S}+\lambda_{T}\right)+2\left(2 \sigma+\lambda_{S}\right)\left(2 \sigma+\lambda_{S}+\lambda_{T}\right)}
$$

In words, (5.4) states that the transaction tax must be small enough not to upset the pattern of trade that emerges in the laissez-faire equilibrium studied in Section 3.

In a market equilibrium with intermediation, the unique distribution of agents $\left\{\mu_{i, j}, v_{i, j}\right\}$ that satisfies the stationarity conditions (3.15)-(3.19) is given by (3.23)-(3.23). Obviously, if the transaction tax is small enough not to upset the pattern of trade that emerges in the laissez-faire equilibrium, the stationary distribution of agents is the same as in the laissez-faire equilibrium.

\subsubsection{Market Equilibrium without Intermediation}

We now look for conditions on the transaction tax $\tau$ under which there is a market equilibrium with the pattern of trade illustrated in Figure 4(b). We refer to this type of equilibrium as an equilibrium without intermediation as it features fundamental trades-i.e., the trades in which the asset moves from low to high-valuation agents-but no intermediation trades-i.e., any trades in which the asset moves between agents with the identical valuation.

In a market equilibrium without intermediation, the after-tax gains from trade between an agent of type $(S, H)$ without the asset and an agent of type $(S, L)$ with the asset are

$$
D_{S, H}-D_{S, L}-\tau=\frac{\Delta u-2 \sigma \tau}{2 \sigma+\lambda_{S}}
$$

The after-tax gains from trade between an agent of type $(T, H)$ without the asset and an agent of type $(T, L)$ with the asset are

$$
D_{T, H}-D_{T, L}-\tau=\frac{\Delta u-2 \sigma \tau}{\left(2 \sigma+\lambda_{S}\right)\left(2 \sigma+\lambda_{S}+\lambda_{T}\right)}
$$

The after-tax gains from trade between an agent of type $(T, H)$ without the asset and an agent of type $(S, L)$ with the asset are

$$
D_{T, L}-D_{S, L}-\tau=\frac{1}{2} \frac{\left(\lambda_{S}+\lambda_{T}\right)(\Delta u-2 \sigma \tau)}{\left(2 \sigma+\lambda_{S}+\lambda_{T}\right)\left(2 \sigma+\lambda_{S}\right)}-\tau .
$$

The after-tax gains from trade between an agent of type $(T, L)$ without the asset and an agent of

\footnotetext{
${ }^{9}$ We assume throughout this section that, if the after-tax gains from trade are zero, agents break the indifference between trading and not trading the asset in favor of trading.
} 
type $(S, L)$ with the asset are

$$
D_{T, H}-D_{S, L}-\tau=\left(1-\frac{1}{2} \frac{\lambda_{S}+\lambda_{T}}{2 \sigma+\lambda_{S}+\lambda_{T}}\right) \frac{\Delta u-2 \sigma \tau}{2 \sigma+\lambda_{S}} .
$$

Moreover, the gains from trade $D_{S, H}-D_{T, L}-\tau$ between a potential buyer of type $(S, H)$ and a potential seller of type $(T, L)$ are equal to those in (5.7), whereas the gains from trade $D_{S, H}-$ $D_{T, H}-\tau$ between a potential buyer of type $(S, H)$ and a potential seller of type $(T, H)$ are equal to those in (5.8).

The pattern of trade in an equilibrium without intermediation is individually rational if and only if the after-tax gains from trade are positive in every meeting where trade is supposed to take place, and strictly negative in every meeting where trade is supposed not to take place. All of the conditions under which the pattern of trade is individually rational are satisfied if and only if (5.5)-(5.7) are positive and (5.8) is negative. In turn, the gains from trade (5.5)-(5.7) are positive iff

$$
\tau \leq \tau_{3} \equiv \Delta u / 2 \sigma
$$

and the gains from trade (5.8) are negative iff

$$
\tau>\tau_{1} \equiv \frac{\left(\lambda_{S}+\lambda_{T}\right) \Delta u}{2 \sigma\left(\lambda_{S}+\lambda_{T}\right)+2\left(2 \sigma+\lambda_{S}\right)\left(2 \sigma+\lambda_{S}+\lambda_{T}\right)} .
$$

Conditions (5.9) and (5.10) state that the tax must be large enough to break the trades between agents of type $S$ and $T$ with the same valuation, but small enough not to upset the trades between agents with low and high valuation. Such a tax always exists, as the right-hand side of (5.9) is greater than the right-hand side of (5.10). There is a simple intuition for this. The transaction tax effectively hits intermediation trades twice, but hits fundamental trades only once. A trade in which $(T, L)$ buys the asset from $(S, L)$ can be valuable only if $(T, L)$ resells the asset to a high-valuation agent at a price higher than the one at which $(S, L)$ could have traded. Similarly, a trade in which $(T, H)$ agent sells the asset to $(S, H)$ can be valuable only if $(T, H)$ repurchases the asset from a low-valuation agent at a price that is lower than the one at which $(S, H)$ could have traded. In other words, for an intermediation trade to be valuable it must be followed by another trade. Thus, the transaction tax hits the value of intermediation trades twice (directly and in the follow-up trade). In contrast, a fundamental trade is valuable even without follow-up trades as it involves moving the asset from a low to a high-valuation agent.

In a market equilibrium without intermediation, the unique stationary distribution of agents $\left\{\mu_{i, j}, v_{i, j}\right\}$ is such that

$$
\mu_{i, L}=v_{i, H}=\phi_{i}\left[\sqrt{\left(\frac{\sigma}{\lambda}\right)^{2}+\frac{\sigma}{2 \lambda}}-\frac{\sigma}{\lambda}\right], \text { for } i=\{S, T\}
$$


and

$$
v_{i, L}=\mu_{i, H}=\phi_{i} / 2-\mu_{i, L}, \text { for } i=\{S, T\} .
$$

Note that the fraction of mismatched agents is the same among agents of type $S$ and $T$. This is intuitive because, in an equilibrium without intermediation, mismatched agents of type $S$ and $T$ readjust their asset position at the same rate. Also, note that the total measure of mismatched agents is the same as in an equilibrium with intermediation. This is intuitive as well because, relative to an equilibrium with intermediation, the only trades that are suppressed are those among agents with the same valuation but different commitment power.

\subsubsection{Market Equilibrium without Trade}

Finally, we look for conditions on the transaction tax $\tau$ under which there is a market equilibrium with the pattern of trade illustrated in Figure 4(c). We refer to this type of equilibrium as an equilibrium without trade for the obvious reason that it does feature neither fundamental trades between low and high-valuation agents, nor intermediation trades between agents with the same valuation and different commitment power.

In a market equilibrium without trade, the after-tax gains from trade between any type of high-valuation agent without the asset and any type of low-valuation agent with the asset are

$$
D \cdot, H-D \cdot, L-\tau=(\Delta u-2 \sigma \tau) /(2 \sigma) .
$$

The after-tax gains from trade between any two low-valuation agents or between any two highvaluation agents are

$$
D_{, L}-D \cdot, L-\tau=D \cdot, H-D \cdot, H-\tau=-\tau \text {. }
$$

The above expressions are intuitive. In an equilibrium without trade, whenever two agents consider exchanging the asset, they understand that they will never readjust their inventories again. Thus, the gains from trade between a low-valuation agent with the asset and a highvaluation agent without the asset are equal to the capitalized change in their flow utility net of the transaction tax. And the gains from trade between two agents with the same valuation are equal to the negative of the transaction tax.

The pattern of trade in a market equilibrium without trade is individually rational if and only if the after-tax gains from trade are strictly negative in every meeting. These conditions hold iff

$$
\tau>\tau_{3} \equiv \Delta u / 2 \sigma
$$

In words, (5.15) states that the transaction tax must be larger than the capitalized value of reallocating, once and for all, the asset from a low to a high-valuation agent.

In a market equilibrium without trade, any stationary distribution of agents $\left\{\mu_{i, j}, v_{i, j}\right\}$ is 
such that

$$
\begin{aligned}
\mu_{S, j}+\mu_{T, j} & =1 / 4, \text { for } j=\{L, H\} \\
\mu_{i, j}+v_{i, j} & =\phi_{i} / 2, \text { for } j=\{L, H\}, i=\{S, T\} .
\end{aligned}
$$

In words, (5.16)-(5.17) state that half of the asset is allocated to agents with a low valuation, and the other half is allocated to agents with a high valuation. This is intuitive because, in a no-trade equilibrium, any agent who entered the market with the asset keeps it forever and spends half of the time in the low-valuation state and the other half of the time in the high-valuation state.

Using the value of the stationary distribution $\left\{\mu_{i, j}, v_{i, j}\right\}$ in (3.23)-(3.26), (5.11)-(5.12) and (5.16)-(5.17), we can substitute $\lambda_{S}$ and $\lambda_{T}$ out of the conditions (5.4), (5.9)-(5.10) and (5.15) for the existence different types of equilibria. This leads to the following proposition, which summarizes the effect of a transaction tax on the market equilibrium.

Proposition 10 Market Equilibrium with Transaction Tax. For any given $\phi_{T} \in[0,1]$, the cutoffs $\tau_{1}, \tau_{2}$ and $\tau_{3}$ are such that $0<\tau_{1} \leq \tau_{2} \leq \tau_{3}$ and: (i) For $\tau \in\left[0, \tau_{2}\right]$, there exists a market equilibrium with intermediation; (ii) For $\tau \in\left(\tau_{1}, \tau_{3}\right]$, there exists a market equilibrium without intermediation; (iii) For $\tau>\tau_{3}$, there exists a market equilibrium with no trade; (iv) There are no other symmetric stationary market equilibria.

\subsection{Intermediation Equilibrium}

Here, we examine the effect of the transaction tax on the equilibrium measure of intermediaries. In a market equilibrium with intermediation, the benefit of commitment is

$$
\begin{aligned}
b\left(\phi_{T}\right) & =\left[\frac{\lambda_{S}}{2 \sigma+\lambda_{S}}+\frac{\lambda_{T}}{2 \sigma+2 \lambda_{S}+\lambda_{T}}\right] \frac{\Delta u}{4} \\
& -\left[\frac{\lambda_{S} \sigma}{2\left(2 \sigma+\lambda_{S}\right)}+\frac{\lambda_{T}\left(\sigma+\lambda_{S}\right)}{2 \sigma+2 \lambda_{S}+\lambda_{T}}+\lambda_{S}\right] \frac{\tau}{2},
\end{aligned}
$$

where $\lambda_{i}=\lambda \mu_{i, L}$ and $\mu_{i, L}$ is given by (3.22)-(3.23). The expression in (5.18) is the difference of two terms. The first term is the benefit of commitment under laissez-faire. The second term is positive and proportional to $\tau$. Intuitively, a higher $\tau$ lowers $b$ because it reduces the after-tax surplus that can be captured by agents with commitment, and because it hits twice the intermediation trades carried out by agents with commitment. Since the expression in (5.18) is smaller than the benefit of commitment under laissez-faire, so is the equilibrium measure of agents that invest in the commitment technology.

In a market equilibrium without intermediation, the benefit of commitment is

$$
b\left(\phi_{T}\right)=\left[\lambda_{S}+\lambda_{T} \frac{2 \sigma}{2 \sigma+\hat{\lambda}}\right] \frac{\sigma(\Delta u-2 \sigma \tau)}{2\left(2 \sigma+\lambda_{S}\right)^{2}},
$$


where $\lambda_{i}=\lambda \mu_{i, L}$ and $\mu_{i, L}$ is given by (5.11)-(5.12). The expression in (5.19) is positive. Intuitively, the benefit of commitment is positive because, even though, agents with commitment do not carry out any intermediation trades, they still capture a larger share of the surplus when carrying out fundamental trades. The expression in (5.19) is proportional to $\Delta u-2 \sigma \tau$ and, hence, decreasing in $\tau$. Intuitively, a higher $\tau$ lowers $b$ because it reduces the after-tax surplus that can be captured by agents with commitment. Moreover, note that, since the expression in (5.19) is smaller than the benefit of commitment under laissez-faire, so is the equilibrium measure of agents that invest in the commitment technology.

Finally, in a market equilibrium without trade, the benefit of commitment is $b\left(\phi_{T}\right)=0$. This is obvious. In an equilibrium without trade, a meeting between any two agents has negative after-tax gains from trade and, hence, acquiring commitment power to capture more of the gains from trade is worthless. Thus, the equilibrium measure of intermediaries is zero.

We have thus completed the proof of the following proposition.

Proposition 11 Intermediation Equilibrium and Transaction Tax. Introducing a transaction $\operatorname{tax} \tau>0$ lowers the benefit of commitment and the equilibrium measure of intermediaries.

\subsection{Optimal Transaction Tax}

We conclude the section by studying the transaction tax that maximizes the average utility across all agents in the market. Suppose that the transaction tax $\tau$ is set to

$$
\tau^{*}=\Delta u / 2 \sigma
$$

When $\tau=\tau^{*}$, the unique market equilibrium is such that the only trades taking place are those in which low-valuation agents sell the asset to high-valuation agents. In this type of market equilibrium, the benefit $b\left(\phi_{T}\right)$ to an individual agent from acquiring the commitment technology is given by (5.19), which is equal to zero when $\tau=\tau^{*}$. Therefore, when $\tau=\tau^{*}$, the unique intermediation equilibrium is such that $\phi_{T}=0$. That is, none of the agents in the market acquires the commitment technology.

From the above observations, it follows that, when $\tau=\tau^{*}$, welfare is given by

$$
W=\frac{u_{H}}{2}-\left[\sqrt{\frac{\sigma^{2}}{\lambda^{2}}+\frac{\sigma}{2 \lambda}}-\frac{\sigma}{\lambda}\right] \Delta u .
$$

Comparing (5.21) and (4.11) immediately reveals that welfare in an equilibrium with a transaction $\operatorname{tax} \tau^{*}$ is equal to welfare in an efficient allocation. Indeed, with a transaction tax $\tau^{*}$, the equilibrium satisfies the two conditions for efficiency. Namely: (i) In any meeting between 
a low and a high-valuation agent, the ownership of the asset goes to the high-valuation agent; (ii) The measure of agents who acquire the commitment technology is zero. Since welfare in equilibrium is equal to welfare in the efficient allocation, it also follows that $\tau^{*}$ is the optimal transaction tax.

We have established the following proposition.

Proposition 12 Optimal Transaction Tax. For any cost of commitment $c>0$ : (i) The transaction tax that maximizes welfare is $\tau^{*}$; (ii) Given the transaction tax $\tau^{*}$, equilibrium is efficient.

A couple of observations about Proposition 12 are in order. First, note that the defining feature of the optimal transaction tax $\tau^{*}$ is that the gains from trade in a meeting between a low-valuation seller and a high-valuation buyer are equal to zero. This feature of the optimal transaction tax is easy to understand. In a Walrasian equilibrium, the gains from trade between a low-valuation seller and a high-valuation buyer are equal to zero, because the seller can unload the asset at the market price without delay and the buyer can purchase the asset at the same market price without delay. And it is because the gains from trade are zero that, in a Walrasian equilibrium, the commitment power of an agent is worthless. The optimal transaction tax reproduces this feature of Walrasian equilibrium in an environment where neither the buyer nor the seller can trade at a market price without delay.

Second, note that the transaction tax $\tau^{*}$ attains the efficient allocation. Therefore, richer mechanisms that allow the transaction tax to vary with the identity of the traders, the history of the traders, etc... would not lead to any improvement upon a simple mechanism in which the transaction tax is the same in every trade. In other words, if we solved for the mechanism design problem rather than for the optimal unconditional tax, we would still find that the tax $\tau^{*}$ is the optimum. Moreover, note that to implement the transaction tax $\tau^{*}$ it is sufficient to observe that a trade has taken place. Therefore, the transaction tax $\tau^{*}$ is the optimal mechanism in any environment in which trade is publicly observable. In particular, it is optimal in environments where the traders' identity and history is also public, in environments where the traders' identity is private while their history is public, as well as in environments where the traders' identity and history are both private. Clearly, though, if we were to consider a richer model (in which the agents' valuation for the asset takes more than two values, in which agents differ with respect to their contact rate, etc...) the transaction tax $\tau^{*}$ would no longer be enough to deliver constrained efficiency.

Finally, note that Proposition 12 is related to a large literature advocating for transaction taxes in financial markets. In this literature, the rationale for transaction taxes is either that the price of financial assets is inefficiently volatile (e.g., Keynes 1936 and, more recently, Tobin 1978, Summers and Summers 1989) or that participants in financial markets have an incentive 
to invest too many resources in acquiring private information about the quality of various assets (see, e.g., Stiglitz 1989). The rationale behind the optimality of the transaction tax in Proposition 12 is that, in a financial market where trade is subject to search frictions (however small), agents have an incentive to invest resources in technologies that allow them to extract a larger share of the gains from trade, even though such rent-extraction activity is at best worthless and, at worst, detrimental from the aggregate perspective.

\section{Conclusions}

The paper examined the consequences on the equilibrium of a frictional asset market when the agents participating in the market are heterogeneous in their bargaining skills. First, we showed that agents with superior bargaining skills-i.e., those who can commit to take-it-orleave-it offers-become intermediaries and the agents with inferior bargaining skills-i.e., those who cannot commit to their offer-become final users. Agents with commitment trade the asset on behalf of agents without commitment not because they are faster at finding a buyer, not because they have lower holding costs or a higher valuation. They do so only because they can extract more rents when they resell the asset to a third party. In this sense, heterogeneity in bargaining skills leads to a theory of intermediation as a pure rent extraction activity. Second, we showed that, when agents can acquire bargaining skills at a cost, there are typically multiple equilibria, which differ with respect to the fraction of intermediaries in the market. Equilibrium multiplicity is caused by a local strategic complementarity in the agents' decisions to acquire bargaining skills. Third, we showed that equilibria with more intermediaries are associated with lower welfare and any equilibrium with any intermediation is inefficient. Equilibrium inefficiency is caused by the fact that the intermediation activity carried out by agents with better bargaining skills does not serve any role in improving the allocation of the asset, but acquiring bargaining skills is costly. Fourth, we showed that, when trading frictions become smaller, the fraction of intermediaries grows. This surprising result is due to the fact that a decline in trading frictions increases the arrival rate of opportunities for rent-extraction more than it lowers the size of the rents that can be extracted from each final user. Moreover, when trading frictions become smaller, welfare falls at any interior equilibrium. Similarly, we showed that, when the interest rate falls, the fraction of intermediaries grows and welfare declines. Finally, we showed that a simple transaction tax can restore efficiency by artificially reproducing a key feature of a Walrasian market. Namely, that the gains from trade between any two traders are zero and, hence, there is no scope for bargaining. 


\section{References}

[1] Burdett, K., and M. Coles. 1997. "Marriage and Class". Quarterly Journal of Economics, 112: $141-168$

[2] Burdett, K., and K. Judd. 1983. "Equilibrium Price Dispersion.” Econometrica, 51: 95570.

[3] Burdett, K., and D. Mortensen. 1998. "Wage Differentials, Employer Size, and Unemployment." International Economic Review, 39: 257-73.

[4] Cociuba, S., M. Shukayev and A. Ueberfeldt. 2016. "Collateralized Borrowing and Risk Taking at Low Interest Rates," European Economic Review, 85: 62-83.

[5] Diamond, P. 1971. “A Model of Price Adjustment.” Journal of Economic Theory, 3: 156168.

[6] Diamond, P. 1982. "Aggregate Demand Management in Search Equilibrium.” Journal of Political Economy, 90: 881-94.

[7] Duffie, D., N. Gârleanu, and L. Pedersen. 2005. “Over-the-Counter Markets,” Econometrica, 73: 1815-1847.

[8] Farboodi, M., G. Jarosch and G. Menzio. 2016. “Intermediation as Rent Extraction.” PIER Working Paper 16-026.

[9] Farboodi, M., G. Jarosch and R. Shimer. 2017. "The Emergence of Market Structure." Mimeo, University of Chicago.

[10] Harris Poll, 2014. "Doctors, Military Officers, Firefighters, and Scientists Seen as Among America's Most Prestigious Occupations."

[11] Hosios, A. 1990. "On the Efficiency of Matching and Related Models of Search and Unemployment." Review of Economic Studies, 57: 279-298

[12] Hugonnier, J., B. Lester and P. Weill. 2016. "Heterogeneity in Decentralized Asset Markets.” Mimeo, University of California Los Angeles.

[13] Jiménez, G., S. Ongena, J. Peydró and J. Saurina. 2014. "Hazardous Times for Monetary Policy: What Do Twenty-Three Million Bank Loans Say About the Effects of Monetary Policy on Credit Risk-Taking?" Econometrica, 82: 463-505.

[14] Kaplan, G., and G. Menzio. 2016. "Shopping Externalities and Self-Fulfilling Unemployment Fluctuations." Journal of Political Economy, 124: 771-825 
[15] Keynes, J. 1936. “The General Theory of Employment, Interest, and Money.” Macmillan, UK.

[16] Kyiotaki, N., and R. Wright. 1989. “On Money as a Medium of Exchange.” Journal of Political Economy, 97: 927-954.

[17] Lagos, R., and G. Rocheteau. 2007. "Search in Asset Markets: Market Structure, Liquidity, and Welfare.” American Economic Review, 97: 198-202.

[18] Lagos, R., and G. Rocheteau. 2009. "Liquidity in Asset Markets with Search Frictions." Econometrica, 77: 403-426

[19] Masters, A. 2008. "Unpleasant Middlemen," Journal of Economic Behavior and Organization, 68: 581-594.

[20] Mortensen, D. 1982. "Property Rights and Efficiency in Mating, Racing, and Related Games". American Economic Review, 72: 968-979.

[21] Mortensen, D. 1999. "Equilibrium Unemployment Dynamics.” International Economic Review, 40: 889-914.

[22] Mortensen, D., and C. Pissarides. 1994. "Job Creation and Job Destruction in the Theory of Unemployment." Review of Economic Studies, 61: 397-415.

[23] Nosal, E., R. Wright and Y. Wong. 2015. "More on Middlemen: Equilibrium Entry and Efficiency in Intermediated Markets." Journal of Money, Credit and Banking, 47: 7-37.

[24] Nosal, E., R. Wright and Y. Wong. 2016. "Who Wants to be a Middleman?" Mimeo, University of Wisconsin Madison.

[25] Philippon, T. 2015. "Has the US Financial Industry Become Less Efficient?” American Economic Review, 105: 1408-1438.

[26] Postel-Vinay F., and J. Robin. 2002. "Equilibrium Wage Dispersion with Worker and Employer Heterogeneity." Econometrica, 70: 2295-2350.

[27] Rajan, R. 2006. “Has Finance Made the World Riskier?” European Financial Management, 12: 499-533.

[28] Rubinstein, A. 1982. "Perfect Equilibrium in a Bargaining Model." Econometrica, 50: 97-109.

[29] Rubinstein, A., and A. Wolinsky. 1987. “Middlemen," Quarterly Journal of Economics, 102: 581-594. 
[30] Stiglitz, J. 1989. "Using Tax Policy To Curb Speculative Short-Term Trading." Journal of Financial Services Research, 2-3: 101-115.

[31] Summers, L. and V. Summers. 1989. "When financial markets work too well: A cautious case for a securities transactions tax.” Journal of Financial Services Research, 3: 261-286.

[32] Tobin, J. 1978. “A Proposal for Monetary Reform.” Eastern Economics Journal, 4: 153159.

[33] Üslü, S. 2016. "Pricing and Liquidity in Decentralized Asset Markets.” Mimeo, University of California Los Angeles.

[34] Wright, R., and Y. Wong. 2014. "Buyers, Sellers, and Middlemen: Variations on SearchTheoretic Themes." International Economic Review, 55: 375-397. 


\section{Appendix}

\section{A Uniqueness of Market Equilibrium}

A stationary market equilibrium is symmetric if and only if $\mu_{i, L}=v_{i, H}$ for $i=\{S, T\}$. From the inflow-outflow conditions (3.15)-(3.16) and the fact that a potential buyer and a potential seller exchange the asset if and only if the gains from trade are positive, it follows that $\mu_{i, L}=v_{i, H}$ for $i=\{S, T\}$ if and only if agents of the same commitment type have the lowest and highest net valuations of the asset. Therefore, there are 8 possible patterns of trade that are consistent with the symmetry condition. These 8 possible patterns of trade are fully characterized by following chains of inequalities: (i) $D_{S, L} \leq D_{T, L} \leq D_{T, H} \leq D_{S, H}$; (ii) $D_{T, L} \leq D_{S, L} \leq D_{S, H} \leq D_{T, H}$; (iii) $D_{S, L} \leq D_{T, H} \leq D_{T, L} \leq D_{S, H}$; (iv) $D_{T, H} \leq D_{S, L} \leq D_{S, H} \leq D_{T, L}$; (v) $D_{S, H} \leq D_{T, L} \leq D_{T, H} \leq D_{S, L}$; (vi) $D_{S, H} \leq D_{T, H} \leq D_{T, L} \leq D_{S, L}$; (vii) $D_{T, L} \leq D_{S, H} \leq D_{S, L} \leq D_{T, H}$; (viii) $D_{T, H} \leq D_{S, H} \leq D_{S, L} \leq$ $D_{T, L}$.

We first rule out the existence of a symmetric stationary equilibrium with $D_{S, H} \leq D_{S, L}$. This eliminates the equilibria (v)-(viii)..To this aim, note that in any equilibrium the lifetime utilities of an agent of type $(S, L)$ who does and does not own the asset respectively satisfy

$$
\begin{gathered}
r V_{S, L}=u_{L}+\sigma\left(V_{S, H}-V_{S, L}\right)+\lambda_{S} \max \left\{D_{S, H}-D_{S, L}, 0\right\} / 2 . \\
r U_{S, L}=\sigma\left(U_{S, H}-U_{S, L}\right)+\hat{\lambda}_{S} \max \left\{D_{S, L}-D_{S, H}, 0\right\} / 2 .
\end{gathered}
$$

The lifetime utilities of an agent of type $(S, H)$ who does and does not own the asset respectively satisfy

$$
\begin{gathered}
r V_{S, H}=u_{H}+\sigma\left(V_{S, L}-V_{S, H}\right)+\hat{\lambda}_{S} \max \left\{D_{S, L}-D_{S, H}, 0\right\} / 2 . \\
r U_{S, H}=\sigma\left(U_{S, L}-U_{S, H}\right)+\lambda_{S} \max \left\{D_{S, H}-D_{S, L}, 0\right\} / 2 .
\end{gathered}
$$

From (A.1)-(A.4), it follows that $D_{S, H}-D_{S, L}$ is given by

$$
\begin{aligned}
(r+2 \sigma)\left(D_{S, H}-D_{S, L}\right) & =\Delta u-\lambda_{S} \max \left\{D_{S, H}-D_{S, L}, 0\right\} \\
& +\hat{\lambda}_{S} \max \left\{D_{S, L}-D_{S, H}, 0\right\}
\end{aligned}
$$

If $D_{S, H} \leq D_{S, L},(\mathrm{~A} .5)$ implies

$$
D_{S, H}-D_{S, L}=\frac{\Delta u}{r+2 \sigma+\hat{\lambda}_{S}} .
$$

The expression in (A.6) is clearly strictly positive. Therefore, if $D_{S, H} \leq D_{S, L}, D_{S, H}>D_{S, L}$ which is a contradiction. Therefore, in any market equilibrium $D_{S, H}>D_{S, L}$. 
Next, we rule out the existence of a symmetric stationary equilibrium with $D_{T, H} \leq D_{T, L}$. This eliminates the equilibria (iii) and (iv). To this aim, note that in any equilibrium the lifetime utilities of an agent of type $(T, L)$ who does and does not own the asset respectively satisfy

$$
\begin{aligned}
& r V_{T, L}=u_{L}+\sigma\left(V_{T, H}-V_{T, L}\right)+\lambda_{S} \max \left\{D_{S, H}-D_{T, L}, 0\right\} \\
& \quad+\hat{\lambda}_{S} \max \left\{D_{S, L}-D_{T, L}, 0\right\}+\lambda_{T} \max \left\{D_{T, H}-D_{T, L}, 0\right\} / 2
\end{aligned}
$$

and

$$
\begin{aligned}
& r U_{T, L}=\sigma\left(U_{T, H}-U_{T, L}\right)+\hat{\lambda}_{S} \max \left\{D_{T, L}-D_{S, H}, 0\right\} \\
& \quad+\lambda_{S} \max \left\{D_{T, L}-D_{S, L}, 0\right\}+\hat{\lambda}_{T} \max \left\{D_{T, L}-D_{T, H}, 0\right\} / 2 .
\end{aligned}
$$

Using (A.7)-(A.8) and the analogous expressions for an agent of type $(T, H)$, we can show that $D_{T, H}-D_{T, L}$ is given by

$$
\begin{aligned}
& (r+2 \sigma)\left(D_{T, H}-D_{T, L}\right) \\
= & \Delta u+\hat{\lambda}_{T} \max \left\{D_{T, L}-D_{T, H}, 0\right\}-\lambda_{T} \max \left\{D_{T, H}-D_{T, L}, 0\right\} \\
+ & \lambda_{S} \max \left\{D_{S, H}-D_{T, H}, 0\right\}+\hat{\lambda}_{S} \max \left\{D_{S, L}-D_{T, H}, 0\right\} \\
- & \lambda_{S} \max \left\{D_{S, H}-D_{T, L}, 0\right\}-\hat{\lambda}_{S} \max \left\{D_{S, L}-D_{T, L}, 0\right\} \\
+ & \lambda_{S} \max \left\{D_{T, L}-D_{S, L}, 0\right\}+\hat{\lambda}_{S} \max \left\{D_{T, L}-D_{S, H}, 0\right\} \\
- & \lambda_{S} \max \left\{D_{T, H}-D_{S, L}, 0\right\}-\hat{\lambda}_{S} \max \left\{D_{T, H}-D_{S, H}, 0\right\} .
\end{aligned}
$$

If $D_{T H} \leq D_{T L}$, we can rewrite (A.9) as

$$
\begin{aligned}
(r+ & \left.2 \sigma+\hat{\lambda}_{T}\right)\left(D_{T, H}-D_{T, L}\right)=\Delta u \\
& +\lambda_{S}\left[\max \left\{D_{S, H}-D_{T, H}, 0\right\}-\max \left\{D_{S, H}-D_{T, L}, 0\right\}\right] \\
& +\hat{\lambda}_{S}\left[\max \left\{D_{S, L}-D_{T, H}, 0\right\}-\max \left\{D_{S, L}-D_{T, L}, 0\right\}\right] \\
& +\lambda_{S}\left[\max \left\{D_{T, L}-D_{S, L}, 0\right\}-\max \left\{D_{T, H}-D_{S, L}, 0\right\}\right] \\
& +\hat{\lambda}_{S}\left[\max \left\{D_{T, L}-D_{S, H}, 0\right\}-\max \left\{D_{T, H}-D_{S, H}, 0\right\}\right] .
\end{aligned}
$$

Clearly, the second, third, fourth and fifth lines on the right-hand side of (A.10) are positive. The first line on the right-hand side of (A.10) is strictly positive. Therefore, if $D_{T, H} \leq D_{T, L}$, $D_{T, H}>D_{T, L}$ which is a contradiction. Therefore, in any market equilibrium $D_{T, H}>D_{T, L}$.

Finally, we rule out the existence of a symmetric stationary equilibrium with $D_{T, H} \leq D_{T, L}$. This eliminates the equilibrium (ii). To this aim, note that, using the expressions (A.1)-(A.4) and (A.7)-(A.8), we can write $D_{T, H}-D_{T, L}$ as

$$
\begin{aligned}
r\left(D_{T, L}-D_{S, L}\right) & =\sigma\left(D_{T, H}-D_{T, L}\right)-\sigma\left(D_{S, H}-D_{S, L}\right) \\
& +\lambda_{T}\left(D_{T, H}-D_{T, L}\right) / 2-\lambda_{S}\left(D_{S, H}-D_{S, L}\right) / 2 \\
& +\hat{\lambda}_{S} \max \left\{D_{S, L}-D_{T, L}, 0\right\}-\lambda_{S} \max \left\{D_{T, L}-D_{S, L}, 0\right\} \\
& +\lambda_{S} \max \left\{D_{S, H}-D_{T, L}, 0\right\} .
\end{aligned}
$$

Note that the last line must be strictly positive, or else we would have $D_{S, L}<D_{S, H} \leq D_{T, L}<$ 
$D_{T, H}$ which implies a non-symmetric distribution. ${ }^{10}$ If $D_{T, L} \leq D_{S, L}, D_{S, H} \leq D_{T, H}$ and we can rewrite (A.11) as

$$
\begin{aligned}
& \left(r+\hat{\lambda}_{S}\right)\left(D_{T, L}-D_{S, L}\right) \\
= & \sigma\left(D_{T, H}-D_{T, L}\right)-\sigma\left(D_{S, H}-D_{S, L}\right) \\
+ & \lambda_{T}\left(D_{T, H}-D_{T, L}\right) / 2-\lambda_{S}\left(D_{S, H}-D_{S, L}\right) / 2+\lambda_{S}\left(D_{S, H}-D_{T, L}\right) .
\end{aligned}
$$

In turn, (A.12) can be rewritten as

$$
\begin{aligned}
& \left(r+\hat{\lambda}_{S}\right)\left(D_{T, L}-D_{S, L}\right) \\
= & \sigma\left[\left(D_{T, H}-D_{T, L}\right)-\left(D_{S, H}-D_{S, L}\right)\right] \\
+ & \lambda_{T}\left(D_{T, H}-D_{T, L}\right) / 2+\lambda_{S}\left(D_{S, H}-D_{S, L}\right) / 2 .
\end{aligned}
$$

Note that the right-hand side of (A.13) is strictly positive. Therefore, if $D_{T, L} \leq D_{S, L}, D_{T, L}>D_{S, L}$ which is a contradiction. Therefore, in any market equilibrium $D_{T, L}>D_{S, L}$.

\section{B Inefficiency of Market Equilibrium}

\section{B.1 Transaction Cost}

In the version of the model described in example 1 (transaction cost), we obtain the following expressions for the gains from trade:

$$
\begin{gathered}
D_{S H}-D_{S L}-c=\frac{\Delta u-2 \sigma c}{r+2 \sigma+\lambda_{S}}, \\
D_{T H}-D_{T L}-c=\frac{\Delta u-2 \sigma c}{r+2 \sigma+\lambda_{T}+2 \lambda_{S}}, \\
D_{T L}-D_{S L}-c=D_{S H}-D_{T H}-c=\frac{1}{2} \frac{\Delta u-2 \sigma c}{r+2 \sigma+\lambda_{S}} \frac{\lambda_{T}+\lambda_{S}}{r+2 \sigma+2 \lambda_{S}+\lambda_{T}} .
\end{gathered}
$$

It is immediate to verify that, for $c$ small enough, the expressions in (B.1)-(B.3) are all strictly positive. Therefore, the equilibrium pattern of trade is the same as in Figure 1.

\section{B.2 Richer Preferences}

In the version of the model described in example 2 (richer preferences), we obtain the following expressions for the gains from trade:

$$
D_{S H}-D_{S L}=\frac{\Delta u}{r+2 \sigma+\lambda_{S}},
$$

\footnotetext{
${ }^{10}$ It is possible but tedious to show that this non-symmetric market equilibrium cannot exist either.
} 


$$
\begin{gathered}
D_{T H}-D_{T L}=\frac{\Delta u-\varepsilon}{r+2 \sigma+\lambda_{T}+2 \lambda_{S}}, \\
D_{T L}-D_{S L}=D_{S H}-D_{T H}=\frac{1}{2}\left[\frac{\Delta u\left(\lambda_{T}+\lambda_{S}\right)}{r+2 \sigma+2 \lambda_{S}}-\varepsilon\right] \frac{1}{r+2 \sigma+2 \lambda_{S}+\lambda_{T}} .
\end{gathered}
$$

It is immediate to verify that, for $\varepsilon$ small enough, the expressions in (B.4)-(B.6) are all strictly positive. Therefore, the equilibrium pattern of trade is the same as in Figure 1.

\section{B.3 Heterogeneity in Contact Rates}

In the version of the model described in example 3 (heterogeneity in contact rates), we obtain the following expressions for the gains from trade:

$$
\begin{gathered}
D_{S H}-D_{S L}=\frac{\Delta u}{r+2 \sigma+\lambda_{S}}>0, \\
D_{T H}-D_{T L}=\frac{\Delta u}{r+2 \sigma+\omega\left(\lambda_{T}+2 \lambda_{S}\right)}>0 \\
D_{T L}-D_{S L}=D_{S H}-D_{T H}=\frac{1}{2}\left[\frac{\Delta u \omega\left(\lambda_{T}+2 \lambda_{S}\right)-\lambda_{s}}{r+2 \sigma+2 \lambda_{S}}\right] \frac{1}{r+2 \sigma+\omega\left(2 \lambda_{S}+\lambda_{T}\right)} .
\end{gathered}
$$

It is immediate to verify that, for $\omega$ close enough to 1 , the expressions in (B.7)-(B.9) are all strictly positive. Therefore, the equilibrium pattern of trade is the same as in Figure 1. 